\title{
WestVirginiaUniversity
}

THE RESEARCH REPOSITORY @ WVU

Graduate Theses, Dissertations, and Problem Reports

2017

\section{Comparison of Methods of Measuring Electronic Cigarette Puff Topography}

\author{
Nicholas Felicione
}

Follow this and additional works at: https://researchrepository.wvu.edu/etd

\section{Recommended Citation}

Felicione, Nicholas, "Comparison of Methods of Measuring Electronic Cigarette Puff Topography" (2017). Graduate Theses, Dissertations, and Problem Reports. 5586.

https://researchrepository.wvu.edu/etd/5586

This Thesis is protected by copyright and/or related rights. It has been brought to you by the The Research Repository @ WVU with permission from the rights-holder(s). You are free to use this Thesis in any way that is permitted by the copyright and related rights legislation that applies to your use. For other uses you must obtain permission from the rights-holder(s) directly, unless additional rights are indicated by a Creative Commons license in the record and/ or on the work itself. This Thesis has been accepted for inclusion in WVU Graduate Theses, Dissertations, and Problem Reports collection by an authorized administrator of The Research Repository @ WVU. For more information, please contact researchrepository@mail.wvu.edu. 
Comparison of Methods of Measuring Electronic Cigarette Puff Topography

Nicholas Felicione, B.A.

Thesis submitted to the Eberly College of Arts and Sciences

at West Virginia University

in partial fulfillment of the requirements for the degree of

Master of Science in

Psychology

\author{
Melissa Blank, Ph.D., Chair \\ Steven Kinsey, Ph.D. \\ Nicholas Turiano, Ph.D. \\ Department of Psychology
}

\author{
Morgantown, West Virginia \\ 2016
}

Keywords: electronic cigarette, topography, cigarette smoking, harm reduction Copyright 2016 Nicholas Felicione 


\begin{abstract}
Comparison of Methods of Measuring Electronic Cigarette Puff Topography

Nicholas Felicione
\end{abstract}

To evaluate properly the potential benefits and harms of electronic cigarettes (ECIGs), it is important to evaluate how individuals puff from an electronic cigarette, or their puff topography. This measure, which includes indices of puff number, duration, volume, interpuff interval, and flow rate, can be used to predict exposure to toxicants including nicotine. Puff topography has been studied extensively for cigarette smokers, but not ECIG users. The studies that have involved electronic cigarette topography measurement have done so using devices that have not been thoroughly validated or proven reliable. Thus, the purpose of this study was to evaluate methods of measuring electronic cigarette puff topography. Twelve participants (seven ECIG-experienced users, five ECIG-naïve cigarette smokers) completed three Latin-square ordered sessions that differed by topography measurement method: eTop 2.0, eTop, or natural observation via video recording. Following $\geq 12$ hours of nicotine/tobacco abstinence, participants engaged in three bouts of ECIG puffing: one 10-puff directed bout and two ad lib bouts. Additionally, subjective ratings of nicotine/tobacco withdrawal and product effects were evaluated before and after each ECIG bout. Puff topography did not differ between measurement methods or between groups (p's $>0.05$ ). Measurement of smoking topography differed little between the mouthpiece-based device and direct observation methods. Puff duration, number, and IPI were correlated highly across measurement methods (all $r$ 's $>0.68$ ). All methods were also reliable, as demonstrated by high correlations across cigarette bouts within each condition (most $r$ 's $>0.78$ ). Ratings of withdrawal and product effects changed from baseline to postdirected bout and post-ad lib bout, potentially suggesting nicotine delivery 
from the electronic cigarette. Due to the low sample size, definitive conclusions cannot be determined from this study. Further research should continue to evaluate these measurements with a sample size appropriately powered to detect differences between measurement methods and groups. 


\section{Acknowledgements}

The completion of this thesis project would not have been successful without the contribution and support of multiple people. I would like to thank my advisor, Dr. Melissa Blank, for her support, guidance, and wisdom throughout this project and my time as a graduate student at WVU thus far. I would not be here without her, literally and figuratively. I appreciate the support of Dr. Tom Eissenberg regarding the funding of this project, along with Dr. Alan Shihadeh and Nareg Karaoghlanian for endless correspondence regarding the topography devices. I would also like to acknowledge my committee members, Dr. Steven Kinsey and Dr. Nicholas Turiano, for their expertise and feedback throughout this process. Finally, I would like to thank my lab mates who provided help on this project, Jenny Ozga, Colleen Warren, and Cody Benoit. Particularly, Colleen and Cody put immense effort and countless hours into the video scoring for this project, and I appreciate their commitment to this task.

This work was supported by the collaborative National Institute of Health and Food and Drug Administration grant 3P50DA036105-03S1. The stipend for Nicholas Felicione is provided by NIGMS T32 GM081741. 
Table of Contents

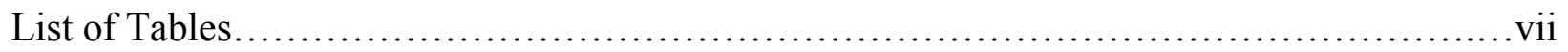

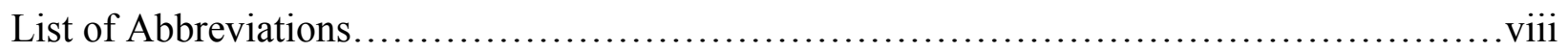

Chapter 1 - Introduction............................................................

Modified Risk Tobacco Products.................................................

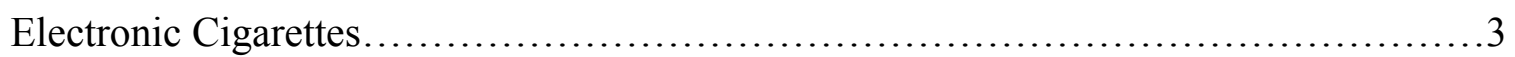

ECIG device and e-liquid characteristics................................ 5

User Characteristics....................................................... 7

Cigarette Topography Measurement............................................... 9

Electronic Cigarette Topography Measurement................................... 10

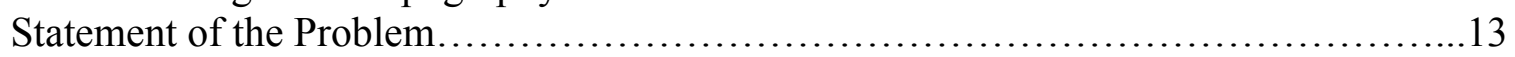

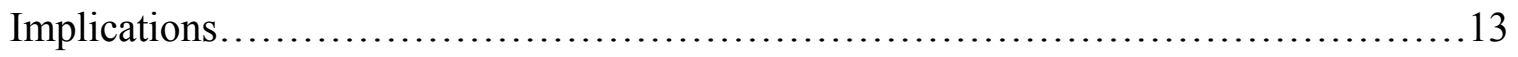

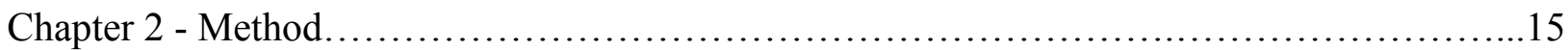

Selection of Participants.................................................... 15

Inclusion Criteria........................................................ 15

Exclusion Criteria.................................................... 15

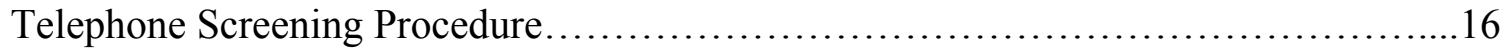

Informed Consent and In-person Screening Procedures...............................16

Study Design.................................................................. 17

Session Procedure.......................................................17

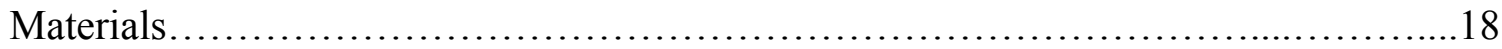

ECIG Devices and e-liquid............................................ 18

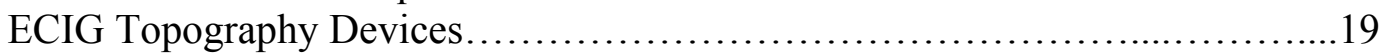

Video Equipment...................................................... 19

Primary Outcome Measures....................................................20

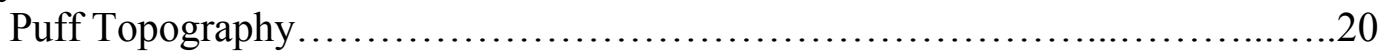

Acceptability Questionnaire..............................................21

Secondary Outcome Measures................................................21

Hughes and Hatsukami Questionnaire.....................................21

Tiffany-Drobes Questionnaire of Smoking Urges............................22

Direct Effects of Nicotine Scale..........................................23

Direct Effects of ECIG Use...............................................23

Physiological Measures.................................................23

Participant Safety and Rights............................................... 24

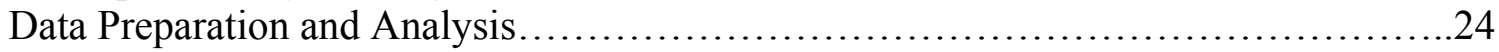

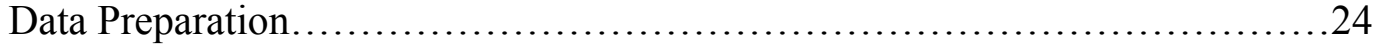

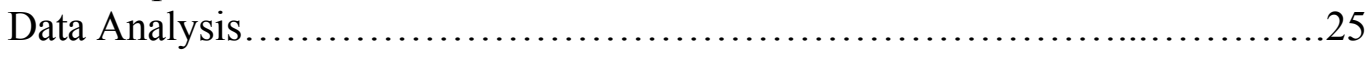

Chapter 3 Results.............................................................. 28

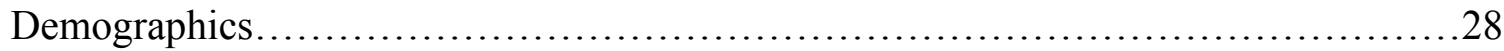

Interrater Reliability ....................................................... 28

Effects of Measurement Method...................................................29 


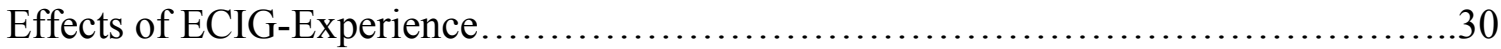

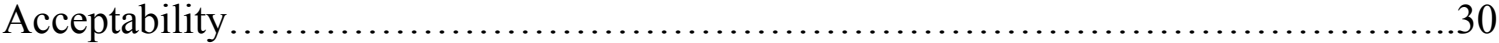

Hughes-Hatsukami Questionnaire..............................................

Tiffany-Drobes QSU.............................................................

Direct Effects of ECIG Use...................................................... 31

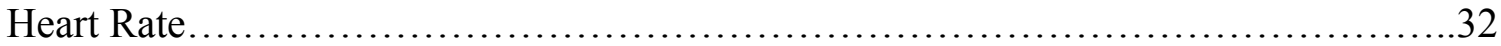

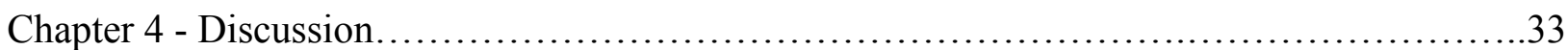

Video-Based Topography Measurement........................................33

Comparisons of Topography Measurement Methods............................... 34

ECIG Experience-Induced Effects............................................ 37

Subjective and Physiological Response..............................................

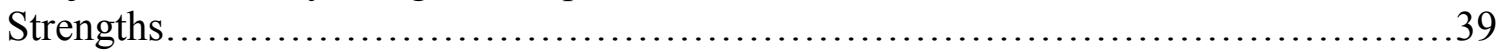

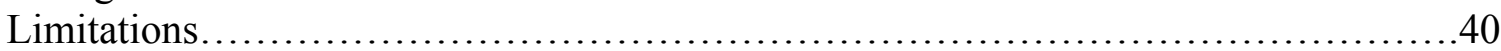

Conclusions and Future Directions..........................................42

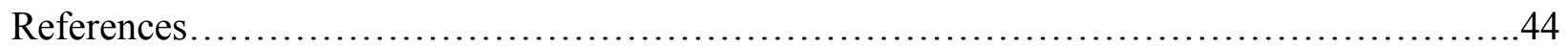

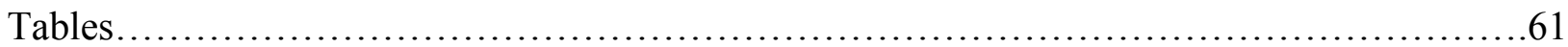

Appendices

Appendix A: Telephone Screening Questionnaire...............................69

Appendix B: Demographic Information....................................... 72

Appendix C: Medical History and Drug Use Form................................. 73

Appendix D: Fagerström Test of Nicotine Dependence........................... 75

Appendix E: Penn State Electronic Cigarette Dependence Index.....................76

Appendix F: Acceptability Questionnaire........................................ 78

Appendix G: Hughes and Hatsukami Questionnaire.................................. 79

Appendix H: Questionnaire of Smoking Urges - Brief........................... 80

Appendix I: Direct Effects of Nictoine Scale....................................82

Appendix J: Direct Effects of ECIG Use....................................... 83 


\section{List of Tables}

Tables

1. Mean (SD) or $\%$ for demographic and product use characteristics................61

2. Correlation coefficients for rater scores by operation definition..................62

3. Statistical analysis results for comparison between measurement methods..........63

4. Correlation coefficients for data collected via computerized device and direct observation methods....................................................64

5. Correlation coefficients for topography via computerized devices and videos of

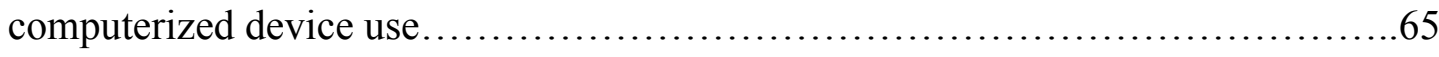

6. Mean (SD) for puff topography measures for device by group $\ldots \ldots \ldots \ldots \ldots \ldots \ldots \ldots 6$

7. Mean (SD) for acceptability items for device by group $\ldots \ldots \ldots \ldots \ldots \ldots \ldots \ldots \ldots \ldots$

8. Mean (SE) for subjective outcomes and heart rate at different timepoints............68 
List of Abbreviations

$\mathrm{CO}$

COPD

CReSS

DENS

FTND

ECIG

IPI

$\mathrm{mg} / \mathrm{ml}$

$\min$

$\mathrm{ml}$

$\mathrm{ml} / \mathrm{sec}$

MRTP

NRT

PG

QSU

sec

U.S.

V

VAS

VG
Carbon Monoxide

Chronic obstructive pulmonary disease

Clinical Research Support System

Direct effects of nicotine scale

Fagerström Test of Nicotine Dependence

Electronic cigarette

Inter-puff interval

milligrams per milliliter

minutes

milliliter

milliliters per second

Modified risk tobacco product

Nicotine replacement therapy

Propylene glycol

Questionnaire of Smoking Urges

seconds

United States

volt

Visual Analog Scale

Vegetable glycerin 


\section{Chapter 1 - Introduction}

Approximately $18 \%$ of adults in the United States (U.S.), or 42 million people, are current cigarette smokers (CDC, 2014). Cigarette smoking accounts for over 480,000 deaths in the U.S. each year, making it the leading preventable cause of disease and death (USDHHS, 2014). Smoking is responsible for almost $90 \%$ of all cases of lung cancer and $80 \%$ of cases of chronic obstructive pulmonary disease (COPD) (USDHHS, 2004). These health problems are directly linked to a variety of harmful chemicals found in tobacco products and tobacco smoke. According to the Food and Drug Administration (FDA, 2012), tobacco smoke contains more than 7,000 chemicals, with 93 classified as harmful or potentially harmful constituents. For example, carbon monoxide $(\mathrm{CO})$ has been linked to cardiovascular and respiratory disease and tobacco-specific nitrosamines have been linked to cancer (USDHHS, 2012).

These risks associated with such tobacco-related diseases are significantly reduced when smokers quit. Specifically, smoking cessation lowers a smoker's risk of death from cardiovascular disease and COPD, and is the only strategy to reduce the development of cancers caused by carcinogens in tobacco smoke (USDHHS, 1990; USDHHS, 2010). Weeks to months after quitting, a smoker's lung function starts to restore, with decreased coughing and shortness of breath (USDHHS, 2004). Fifteen years after quitting, a former smoker's risk of heart disease and stroke is equivalent to that of a non-smoker (IARC, 2007; USDHHS, 2004). Additionally, smokers who achieve complete cessation before age 40 can reduce risk of premature death to levels of a nonsmoker (USDHHS, 1990; USDHHS, 2004). Despite the known benefits of smoking cessation, many smokers are unable to quit. Almost $70 \%$ of current smokers report a desire to quit completely, and each year more than half of smokers make a quit attempt (CDC, 
2011; CDC, 2014). Unfortunately, less than 10\% of smokers successfully quit in a given year (CDC, 2011; Messer, Trinidad, Al-Dalaimy, \& Pierce, 2008).

The difficulty of sustaining smoking cessation might be improved with the use of counseling, nicotine replacement therapy (NRT), and/or non-nicotine prescription medications. In recent years, $31.7 \%$ of smokers used a pharmacotherapy or engaged in counseling to attempt to quit smoking (CDC, 2014). While these approaches may improve cessation rates for some smokers (Cahill, Stevens, Perera, \& Lancaster, 2013; Fiore et al., 2009), their overall impact has been minimal. For example, while smokers who use an NRT product like the lozenge reveal higher initial abstinence rates than smokers who do not use an NRT product, this difference diminishes within six months of use (Fraser et al., 2014). Similarly, the use of varenicline (Chantix $\left.{ }^{\circledR}\right)$, an approved cessation medication for smokers, significantly increases abstinence rates relative to placebo, but not long-term abstinence (Agaboola, Coleman, McNeill, \& Leonardi-Bee, 2015; Aubin et al., 2008; Eisenberg et al., 2008; Gonzales et al., 2006). Additionally, both telephone and face-to-face counseling have failed to increase abstinence rates above pharmacotherapy use or no counseling groups (McCarthy et al., 2008; Sims et al., 2012). Such suboptimal long-term outcomes for currently available treatments have led some smokers to turn to unconventional, and often controversial, products. Collectively, these products have been deemed as Modified Risk Tobacco Products (MRTPs).

\section{Modified Risk Tobacco Products}

MRTPs are products that have been developed and/or marketed as "harm reduction" products (Public Law 111-31, 2009). That is, these products have been touted as a way for smokers to reduce or replace their cigarettes in an attempt to reduce the harms associated with smoking (Stratton et al., 2001). Under this scenario, tobacco-related morbidity and mortality 
rates would decrease despite the continual use of nicotine/tobacco products. For example, tobacco-related health problems are notably lower in Sweden relative to the U.S., though prevalence rates of tobacco snus use among males alone are above 25\% (Norberg, Malmberg, Ng, \& Broström, 2011; Norberg, Malmberg, Ng, \& Broström, 2015). Snus consists of moist tobacco, packaged in a small pouch, that is cured so as to limit formation of carcinogens (i.e., tobacco-specific nitrosamines) (Foulds et al., 2003). Smokers who switch from cigarettes to snus reveal substantially reduced risk for oral cancer, lung cancer, and respiratory and cardiovascular disease, relative to smokers who continue to use cigarettes (Lee, 2013; Luo et al., 2007). Such findings provide support for proponents of the harm reduction approach to tobacco use.

More recently, a popular product promoted as a MRTP is that of an electronic cigarette (ECIG). ECIGs were patented in 2004 and entered the U.S. market in 2007 (Pauly, Li, \& Barry, 2007). Two years later, ECIGs were more commonly searched on the Internet than snus or NRTs (Ayers, Ribisl, \& Brownstein, 2011). Surveys demonstrate that ECIG use has more than doubled among both adolescent and adult samples (CDC, 2013; King, Patel, Nguyen, \& Dube, 2015). While ECIG use is more common among smokers than non-smokers (King et al., 2015; Sutfin, McCoy, Morrell, Hoeppner, \& Wolfson, 2013), a notable portion of never smokers have also tried an ECIG (McMillin et al., 2014). Given their popularity on the U.S. market, the scientific community is eager to learn more about the influence of ECIGs on individual and population health. It remains unknown, however, whether ECIGs have the potential to offer a viable harm reduction strategy for current tobacco users.

\section{Electronic Cigarettes}

The FDA defines ECIGs as a "battery-operated products designed to deliver nicotine, flavor and other chemicals. They turn chemicals, including highly addictive nicotine, into an 
aerosol that is inhaled by the user." (FDA, 2014). All ECIG devices share features of a solution storage component (e.g., tank or cartridge), a battery, a heating element (e.g., resistance wire coil), and a flow sensor (Brown \& Cheng, 2014). Typically, the flow sensor is activated by a change in pressure caused by puffing, leading to activation of the battery. The battery provides power to the heating element, containing a wick saturated in "e-liquid" (solution containing nicotine and other ingredients) and an atomizer to aerosolize the liquid. The user would then inhale the aerosol through the mouthpiece, a process more commonly known as "vaping". Still, the type and combination of these features may vary widely across devices (Brown \& Cheng, 2014).

The first generation of ECIG devices are referred to as "cig-alikes" given that they model the design of a cigarette, with a mouthpiece that resembles a cigarette filter and a LED light that resembles the burning end of the cigarette rod (Cassidy, 2011; Etter, 2012). Cig-alikes may be disposable or reusable (i.e., rechargeable battery and replaceable cartridge) (Cassidy, 2011; Grana et al., 2014). These early devices typically came with cartridges pre-filled with the eliquid solution. The second generation of ECIG devices generally do not resemble traditional cigarettes (Etter, 2012). These ECIGs may hold the e-liquid in a combined cartridge and atomizer (cartomizer) or in a tank system, in which the individual can refill their e-liquid as needed. Second generation ECIGs also have batteries that are manually operated, and usually have a higher voltage capacity than first generation ECIGs (Farsalinos et al., 2014). Also notable is that the user has some freedom to choose the nicotine content (i.e., 0 to $36 \mathrm{mg} / \mathrm{ml}$ ) and the ratio of certain ingredients of their e-liquid.

Importantly, exposure to ECIG ingredients, including nicotine, may be influenced not only by these device and liquid characteristics, but also by user behavior. The amount of nicotine 
emitted per second, the "nicotine flux", is suggested to vary greatly within and across ECIG devices (Shihadeh \& Eissenberg, 2015). For instance, some ECIG designs are unlikely to deliver pharmacologically active doses of nicotine, while other designs are likely to deliver levels of nicotine that far surpass those of a cigarette (Shihadeh \& Eissenberg, 2015). High nicotine flux may expose a user to nicotine concentrations that have the potential to increase dependence or produce toxic outcomes (Shihadeh \& Eissenberg, 2015). Additionally, the user may alter the manner in which they puff on their ECIG in an attempt to circumvent such design features. All of these factors could interact in countless ways to impact user exposure to ECIG ingredients like nicotine, as described below.

ECIG device and e-liquid characteristics. Characteristics of an ECIG that may influence nicotine delivery include battery voltage (Goniewicz, Kuma, Gawron, Knysak, \& Kosmider, 2013; Shihadeh \& Eissenberg, 2015). For example, using digitally produced ECIG puffs, increasing the battery voltage of a cig-alike model from 3.3 volts $(\mathrm{V})$ to $5.2 \mathrm{~V}$ results in higher nicotine yields and increased total particulate matter (i.e., total aerosolized constituents) (Talih et al., 2015). Similarly, increasing the battery voltage of a tank model from $3.3 \mathrm{~V}$ to $5.5 \mathrm{~V}$ increases nicotine yield from $.30 \mathrm{mg}$ to $1.18 \mathrm{mg}$, as well as increases the production of toxic carbonyl compounds (Kosmider et al., 2014a).

Differences in the nicotine yield of ECIGs are also likely impacted by the temperature of the e-liquid (Trehy et al., 2011), which is affected by both the battery and the heating element. Notable is that second generation ECIGs, which result in higher plasma nicotine levels in users, contain higher-capacity batteries and larger atomizers to more effectively provide power to the atomizer (Farsalinos et al., 2014). Another comparison of ECIG types noted the varying efficacy of different ECIGs to aerosolize the relative amount of nicotine present in the e-liquid, with a 
range from $21 \%$ to $85 \%$ (Goniewicz et al., 2013). Trtchounian et al. (2010) reported differences within and across brands of ECIGs in density of aerosol production from the beginning to end of a cartridge, indicating variability in nicotine delivery and constituent exposure. The latter two findings may indicate variability in the heating process both between and within ECIG designs, Manipulations in the content of e-liquid are also implicated in user exposure to nicotine and other constituents. E-liquid usually consists of some combination of nicotine, flavoring, and a humectant, most popularly propylene glycol (PG) and vegetable glycerin (VG) (Hahn et al., 2014). The concentration of these ingredients may be altered, resulting in differential nicotine and toxicant yield between e-liquid brands. Not surprisingly, higher nicotine concentrations lead to higher nicotine yield (Talih et al., 2015) and also higher levels of nicotine delivery to the user (Hiler et al., 2015). Interestingly, the ratio of other ingredients may also affect the nicotine yield of ECIGs. For example, increased levels of PG relative to VG increase the nicotine emitted per puff using machine-generated ECIG puffs (Kosmider et al., 2014a). Additionally, PG may be more susceptible to decomposition at high temperatures compared to VG, resulting in a greater yield of toxic carbonyls (Kosmider et al., 2014b).

A related concern involves the inconsistency between the actual nicotine content of eliquid versus what is listed on the product label (Davis, Dang, Kim, \& Talbot, 2015; Goniewicz et al., 2013; Trehy et al., 2011). The nicotine content of some cartomizers varies by more than $50 \%$ of that labeled (Trehy et al., 2011). Also, some tested e-liquids labeled nicotine showed large variability in the actual nicotine content (Lisko, Tran, Stanfill, Blount, \& Watson, 2015; Trehy et al., 2011). A similar pattern has been observed with the refillable e-liquid for tank system ECIGs, with nicotine concentrations ranging from 1-90\% of the labeled content (Davis et al., 2015; Goniewicz et al., 2013). In fact, some brands of e-liquid labeled as 0mg nicotine 
actually contain upwards of $21 \mathrm{mg}$, and those labeled as $16 \mathrm{mg}$ have contained $6 \mathrm{mg}$ nicotine or less (Trehy et al., 2011).

Regardless of the device or e-liquid features of the ECIG model used, a nicotine dependent user is expected to adapt their behavior to achieve an optimal level of nicotine. Specifically, the manner in which a user puffs on an ECIG may change as a function of the qualities of the device and/or the e-liquid (Shihadeh \& Eissenberg, 2015). This phenomenon, known as compensatory responding, has been demonstrated in the past when cigarette design characteristics are manipulated (Benowitz, 2001; Herning, Jones, Bachman, \& Mines, 1981; Zacny \& Stitzer, 1988). In fact, users' behavior can negate a certain product design features.

User Characteristics. Users' puffing behavior, as measured by puff topography, can be quantified using the variables of puff number, duration (measured in seconds), volume (measured in milliliters), inter-puff interval (IPI; measured in seconds), and flow rate (measured in milliliters per second). Measurement of these topography parameters is crucial for understanding the relationship between nicotine yield (the amount of nicotine able to be emitted from a product) and nicotine delivery (the amount of nicotine absorbed by the user). The importance of topography measurement is demonstrated by the relatively weak correlation between the nicotine yield of a cigarette (regular, light, or ultralight; measured by U.S. Federal Trade Commission) and the plasma nicotine concentration in a user (Benowitz et al., 1983). Light brand cigarettes yield lower levels of nicotine than regular brand cigarettes due to various design features (e.g., vent holes which dilute the smoke upon inhalation). However, smokers' plasma nicotine levels typically do not differ as a function of which cigarette yield they smoke (Benowitz et al., 1983; Kozlowski, O’Connor, Sweeney, 2001). This discrepancy may be explained by user behavior. 
Zacny \& Stitzer (1988) had participants smoke five cigarettes with different nicotine yields $(0.1 \mathrm{mg}-1.1 \mathrm{mg})$, and each cigarette yield was smoked for one week. Increases in average and total puff volume, and decreases in IPI, were associated with lower-yield cigarettes. A similar pattern of results has been demonstrated when smokers of regular, higher-yield cigarettes switch to lower-yield cigarettes. Changes in puffing behavior have been repeatedly demonstrated when a smoker switches to a low-yield cigarette (Blank, Disharoon, \& Eissenberg, 2009; Evans, Buchhalter, Kleykamp, \& Eissenberg, 2003; Hammond, Fong, Cummings, \& Hyland, 2005; Herning et al., 1981). This more intense puffing profile for lower-yield cigarettes has been attributed to the purpose of achieving optimal nicotine levels in the blood (Djordjevic, Hoffman, \& Hoffman, 1997; Sutton et al., 1982). That is, smokers may take more (number), bigger (volume), longer (duration), and/or more frequent (IPI) puffs in order to compensate for the lower levels of nicotine delivered with each puff (Blank et al., 2009; Kozlowski et al., 2001; Zacny \& Stitzer, 1988). Consequently, smokers who switch to lower nicotine yield cigarettes do not expose themselves to lower levels of nicotine or other harmful toxicants (Benowitz, Jacob, Kozlowski, \& Yu, 1986; Hecht et al., 2005). These same compensatory responses may also be observed among ECIG users.

Acute ECIG use by a naïve user seems to be ineffective for nicotine delivery (Vansickel, Cobb, Weaver, \& Eissenberg, 2010). However, similarly designed studies with experienced ECIG users reveal approximately 5-fold increases in plasma nicotine concentrations following acute vaping (Dawkins \& Corcoran, 2014; Vansickel \& Eissenberg, 2013). Additionally, when ECIG-naïve cigarette smokers are followed over 4 weeks of ECIG use, they demonstrate a seemingly improved ability to extract nicotine from the device (Hajek et al., 2015). Specifically, following a 60-min ad lib puffing session at baseline and again at the end of 4 weeks, their peak 
plasma nicotine concentrations increase by a $24 \%$ and their total nicotine intake increases by 79\% (Hajek et al., 2015). Still, none of this early work measured users' topography during ECIG vaping.

Work that does include topography measurement suggests that that ECIG puffing behavior is comparable to cigarette puffing behavior among ECIG-naïve users (Farsalinos et al., 2013; Hua, Yip, \& Talbot, 2013), and that ECIG-naïve users puff differently than ECIGexperienced users (Farsalinos et al., 2013; Spindle et al., 2015b). Smokers and ECIG-naïve users take puffs of approximately two sec in duration (Farsalinos et al., 2013). ECIG-experienced users, however, show puff durations that are generally twice as long (e.g., $>4$ sec; Farsalinos et al., 2013; Hua et al., 2013; Spindle et al., 2015a). Increases in ECIG puff duration are an effective way to increase ECIG nicotine yield (Talih et al., 2015), and may therefore provide an ECIG user with a way to increase nicotine delivery. ECIG users may also learn to increase the volume of each puff and/or lower their flow rates, relative to what is typically observed for cigarette smoking (Spindle et al., 2015a). The research on ECIG puff topography complements earlier research on differential nicotine delivery between users and requires further investigation. Unfortunately, this research has been hampered by the lack of standardized, validated measures for ECIG topography (Evans \& Hoffman, 2014).

\section{Cigarette Topography Measurement}

An understanding of the relationship between nicotine yield and nicotine delivery for cigarette smoking has been facilitated by the development of topography measurement devices. Early measurement methods included direct observation via video recording (Blank et al., 2009; Frederiksen, Miller, \& Peterson, 1977); pneumotachographs (recorded airflow rate to and from the lungs; Gust, Pickens, \& Pechacek, 1983; Zacny et al., 1987); and pocket calculators 
(Henningfield, Yingling, Griffiths, \& Pickens, 1980). Unfortunately, these methods have proven limited in the topography parameters able to be recorded (e.g., puff volume, flow rate) and/or inconvenient in terms of the time and labor required for measurement (Herning et al., 1981; Blank et al., 2009). Most recently, flowmeter designs have been used, as they improve upon the limitations of previous methods (Herning et al., 1981; Puustinen, Olkkonen, Kolonen, \& Tuomisto, 1987).

Currently available flowmeter-based topography devices include the Clinical Research Support System (CReSS) desktop and portable models (Hauni Maschinenbau AG/Borgwaldt $\mathrm{KC}$, Richmond, VA). Both of these computerized devices require that smokers take puffs from a mouthpiece that houses the cigarette. These devices sense the pressure drop that occurs upon inhalation, and then digitize the flow rates using specialized computer software. These devices have been shown to be objective and precise for measuring puff topography in both laboratory (desktop model) and naturalistic (portable model) environments (Buchhalter \& Eissenberg, 2000; Evans et al., 2003; Lee, Malson, Waters, Moolchan, \& Pickworth, 2003). Thus, these devices are now arguably the most widely used for cigarette topography measurement among researchers in the field. Similar devices are now needed for measurement of ECIG topography.

\section{Electronic Cigarette Puff Topography Measurement}

The first study to measure ECIG topography relied on video recording analysis of YouTube videos (Hua et al., 2013). The researchers used a stopwatch to record puff duration and exhale duration for ECIG use within 64 videos of ECIG use and for cigarette smoking within nine videos. Significant differences in puff duration were found between ECIG use $(4.3 \mathrm{sec})$ and cigarette smoking $(2.4 \mathrm{sec})$. Video recordings have also been used for topography measurement in a laboratory setting (Farsalinos et al., 2013; St. Helen et al., 2016). One study involving a 10- 
20 min ad lib puffing bout was recorded for ECIG-experienced users using an ECIG, ECIGnaïve cigarette smokers using an ECIG, and ECIG-naïve cigarette smokers smoking a cigarette (Farsalinos et al., 2013). As was observed via YouTube videos (Hua et al., 2013), puff durations were significantly longer for ECIG use among experienced users than for cigarette smoking (4.2 vs. $2.3 \mathrm{sec}$ ). Additionally, puff durations for ECIG use among ECIG-naïve cigarette smokers (2.1 sec) were comparable to puff durations for cigarette smoking (Hua et al., 2013). More recent research has found average puff durations of $3.5 \mathrm{sec}$ among ECIG-experienced participants during a 90-min, ad lib bout (St. Helen et al., 2016). These studies provided early insights into ECIG topography; however, video recordings cannot capture flow rate and volume. These puffing parameters may be important for understanding users' total exposure to vapor ingredients, as has been shown for cigarette smoking (Benowitz et al., 1986; Djordjevic et al., 1997; Zacny et al., 1987).

Some researchers have attempted to use cigarette topography devices to measure ECIG topography. The portable cigarette topography device (CReSS Pocket) can be fitted with a mouthpiece adaptor to fit an ECIG (Behar, Hua, \& Talbot; 2015). However, the average puff durations among ECIG-experienced users in this work (i.e., $2.6 \mathrm{sec}$ ) conflict with those observed in other studies (e.g., >4 sec; Farsalinos et al., 2013; Hua et al., 2013; Ramôa et al., 2015). This difference may be explained by several limitations noted by the researchers. Notably, e-liquid was pulled into the topography devices for participants who took puffs of longer durations; therefore, these participants were excluded from data analysis (Behar et al., 2015). Additionally, the portable cigarette topography device is programmed to stop recording after 43 puffs, a cutoff that was exceeded by $26 \%$ of participants (Behar et al., 2015). Similar equipment failures leading to substantial data loss have been reported in other work as well (Norton, June, \& O'Connor, 
2014). Such issues demonstrate a need for devices specifically tailored to ECIG topography measurement that have been properly validated.

A recently developed ECIG topography device, the eTop, has been used to examine topography among experienced ECIG users (Eissenberg, 2014; Spindle et al., 2015a). The eTop is a computerized desktop topography device that has been designed to be sensitive to flow rates as low as $2 \mathrm{ml} / \mathrm{sec}$. Plasma nicotine levels were comparable when the ECIG was vaped via the eTop versus when no device was used (natural ECIG vaping). Moreover, these ECIG users revealed an average puff duration of $4.51 \mathrm{sec}$, an average volume of $124.56 \mathrm{ml}$, and an average flow rate of $27.78 \mathrm{ml} / \mathrm{sec}$ during directed bouts, and a mean puff duration of $5.29 \mathrm{sec}$, an average volume of 148.52, and average flow rate of $27.47 \mathrm{ml} / \mathrm{sec}$ during ad lib puffing bouts (Spindle et al., 2016). A similar study that used the eTop to measure ECIG-experienced puff topography during directed bouts found similar results, with slightly longer puffs (approximately $5 \mathrm{sec}$ ) and comparable puff volumes (Ramôa et al., 2015). This topography device has also been used to demonstrate differences in puff duration among ECIG-experienced and ECIG-naïve individuals puffing on an ECIG (Lopez et al., 2016; Ramôa et al., 2015), with ECIG-naïve cigarette smokers taking puffs of less than $3 \mathrm{sec}$. These puffing parameters suggest that this device may provide a more accurate measure of ECIG topography, relative to the cigarette devices.

Some researchers have created new portable, computerized ECIG topography devices (Cunningham et al., 2016; Robinson et al., 2016) or have used ECIGs that measure topography (Dawkins, Kimber, Doig, Feyerabend, \& Cocoran, 2016), however, these devices have not been validated through comparison with other topography devices. These novel measurement methods have yielded different results than what has been demonstrated using the eTop. For example, a one-week study of ECIG-experienced user's puff topography yielded mean puff durations 
ranging from $0.6 \mathrm{sec}$ to $3.4 \mathrm{sec}$ (Robinson et al., 2016), which is notably lower than values captured by the eTop. A similar trend was found using a different novel topography device, with mean puff durations just above 2 sec (Cunningham et al., 2016). However, it is not clear if differences between studies are a function of measurement method, the ECIG used in the study, participant characteristics, or other unidentified factors.

\section{Statement of the Problem}

The ability to measure cigarette topography has been vital to our understanding of how cigarette design features play a role in user exposure to nicotine and other tobacco constituents (Benowitz, 2001). Thus, the application of similar methods to understand the puff topography of ECIG devices is warranted. Existing ECIG topography measurement devices have not been tested thoroughly. It is important to determine whether measurement of ECIG topography interferes with natural puffing behavior, as well as to determine whether these ECIG topography measurement methods are reliable and valid. The purpose of this study, therefore, is to compare ECIG puffing behavior via the ECIG topography devices and natural observation methods.

\section{Implications}

An important implication of this research is to provide researchers with a tool for evaluating ECIG puff topography. Puff topography is a useful predictor of nicotine and toxicant exposure, and is essential in understanding exposure to nicotine and toxicants along with device characteristics (Shihadeh \& Eissenberg, 2015). More specifically, ECIG topography devices will allow for characterization of the interaction between puff topography and ECIG device characteristics on nicotine and toxicant exposure. Currently, researchers are using topography devices that have not been validated in a rigorous manner, and are not engineered specifically to measure ECIG puff topography. Thus, the current project may provide a standardized tool that is 
reliable and valid to reduce differences between studies due to use of different or inaccurate topography devices. In addition, future directions may allow the topography devices to be reduced in size to a portable device, allowing for measurement of ECIG puff topography in the natural environment. 


\section{Chapter 2 - Method}

\section{Selection of Participants}

Participants were recruited through word-of-mouth and university-approved advertisements around the greater Morgantown area. Of those individuals deemed eligible, 7 ECIG-naïve cigarette smokers and 5 ECIG-experienced users completed the study. This sample size is smaller than the number planned ( $n=20$ per group) based on a power analysis using data from previous work that examined ECIG topography between groups with similar inclusion parameters (Spindle et al., 2015a). Those data revealed moderate to large effect sizes for puff duration and volume (Cohen's $\mathrm{f}=0.45$ to 0.79 ; Cohen, 1988 ), the primary outcome measures to be examined in the current study, for between-subjects effects. Effect sizes for other outcome measures of interest are also moderate to large: f's $>0.43$ for subjective withdrawal effects and physiological parameters. Thus, the final sample was likely underpowered to detect many of the desired effects.

Inclusion criteria. Inclusion criteria differed as a function of experimental group. ECIGnaïve cigarette smokers must have reported smoking at least 10 cigarettes per day for at least one year (verified via expired air CO level of no less than 10 ppm; Breland, Buchhalter, Evans, \& Eissenberg, 2002; Cobb, Weaver, \& Eissenberg, 2010), no more than 5 lifetime ECIG uses, and no ECIG use in the past month (Cobb et al., 2010; Hajek et al., 2015; Lechner et al., 2015; Norton et al., 2014). ECIG-experienced users must have reported current ECIG use for at least 3 months, use of at least $1 \mathrm{ml}$ of e-liquid daily with a nicotine concentration no less than $4 \mathrm{mg} / \mathrm{ml}$, and smoking no more than 5 cigarettes per day (as in Spindle et al., 2015a; Vansickel \& Eissenberg, 2013).

Exclusion criteria. Individuals were excluded if they reported a history of medical or 
psychiatric conditions, regular use of most prescription medications (e.g., excluding vitamins and birth control), or use of illicit substances in the past month. Women who reported current breastfeeding or pregnancy, or tested positive for pregnancy via urinalysis, were excluded. These exclusionary criteria have been used successfully in similar research (Blank et al., 2009; Breland et al., 2002; Cobb et al., 2010; Eissenberg, Griffiths, \& Stitzer, 1996; Spindle et al., 2015a).

Telephone screening procedure. Individuals who responded to advertisements were screened initially via telephone interview. Laboratory staff read an approved transcript to explain the study requirements and procedures to interested callers. Individuals were asked to report on basic demographic, medical history, and drug use information (Appendix A). Individuals who appeared eligible based on these questionnaires were asked to visit the laboratory for an inperson screening (as in Blank et al., 2009; Buchhalter \& Eissenberg, 2000; Cobb et al., 2010; Evans et al., 2003).

A total of 90 calls were received from individuals interested in study participation. Of these 90 calls, 66 individuals were deemed ineligible via a telephone-based screening questionnaire. The primary reasons for ineligibility were history of medical or psychiatric conditions ( $\mathrm{n}=24)$, use of $<4 \mathrm{mg} / \mathrm{ml}$ nicotine for ECIG-experienced users $(\mathrm{n}=13)$, and $>5$ lifetime ECIG uses for ECIG-naïve cigarette smokers $(n=20)$.

Informed consent \& in-person screening procedures. Individuals were guided through the informed consent form to demonstrate study purpose, study procedures, and the potential risks and benefits of participation. Those who were willing and able to consent then completed additional screening procedures. The laboratory screening visit consisted of questionnaires similar to those administered via the telephone interview (Appendices B - C). The purpose of these near-identical questions is to ensure reliability of reporting; individuals whose answers 
were conflicting were disqualified from participation. Additionally, cigarette smokers completed the Fagerström Test of Nicotine Dependence (FTND; Appendix D) (Heatherton, Kozlowski, Frecker, \& Fagerström, 1991), with scores of 0 - 3 for minimal dependence, $4-6$ for moderate dependence, and 7 - 10 for high dependence. ECIG users completed the Penn State Electronic Cigarette Dependence Index (Appendix E) (Foulds et al., 2015), with scores of $0-3$ for no dependence, 4 - 8 for low dependence, 9 - 12 for medium dependence, and above 13 for high dependence. Participants’ expired air CO level, measured via piCO+ Smokerlyzer (coVita; Haddonfield, NJ), was sampled to confirm current smoking status. Current cigarette smokers must have provided a $\mathrm{CO}$ level $>10$ ppm, while no cutoff was used for ECIG-experienced users. ECIG use does not cause measurable increases in expired air CO (Yan \& D'Ruiz, 2015; Vansickel et al., 2010), thus making CO level a poor biomarker of ECIG use or abstinence. A trained staff member collected a urine sample from women to test for pregnancy (QuickVue, Quidel Corporation, San Diego, CA). Individuals who met the criteria for participation were scheduled for a session.

\section{Study Design}

This study used a mixed between-within subject design and included three Latin-square ordered sessions. The between-subjects factor was ECIG experience: ECIG-naïve cigarette smokers and ECIG-experienced users. Within-subjects factors were topography measurement method (eTop, eTop 2.0, and natural observation), bout (1-3), and time (pre- and post-ECIG bout for subjective and physiological outcomes).

Session procedure. Participants visited the laboratory for three, approximately 2-hour sessions. Sessions were separated by a minimum of 48 hours to avoid carryover effects (as in Breland et al., 2002; Eissenberg et al.,1996; Lechner et al., 2015; Spindle et al., 2015a). 
Participants were asked to abstain from all nicotine and tobacco products for 12 or more hours before a study session. Overnight abstinence was expired air CO $(\leq 10$ ppm; Blank et al., 2009; Spindle et al., 2015a; Tackett et al., 2015). The session began with continuous recording of heart rate and blood pressure. Thirty min later, participants completed baseline questionnaires that assess nicotine/tobacco withdrawal symptoms and direct nicotine effects. Next, participants were asked to take 10 puffs from their ECIG using a standardized puffing procedure. Specifically, each puff was separated by $30 \mathrm{sec}$ with laboratory staff guiding the procedure (as in Vansickel et al., 2010; Vansickel \& Eissenberg, 2013; Spindle et al., 2015a). Depending on the condition, participants puffed on their ECIG using the ECIG topography devices or no device (i.e., naturally). All sessions were videotaped. Immediately following the guided bout, participants again completed questionnaires that assess withdrawal symptoms and direct nicotine effects. This same procedure (questionnaires, ECIG use, and questionnaires) was repeated for two additional bouts, with 30 min separating each bout. However, for these last two bouts, participants were permitted to puff on their ECIG ad lib for $5 \mathrm{~min}$. At the end of session, participants completed a final questionnaire that assessed their perceived acceptability of measurement method (as in Blank et al., 2009; Spindle et al., 2015a). Participants were compensated $\$ 50$ for session 1, $\$ 75$ for session 2, and $\$ 75$ for session 3, totaling $\$ 200$.

\section{Materials}

ECIG devices and e-liquid. As in previous work (Spindle et al., 2015b), all participants used the e-GO 3.3 V, 1000mAh battery (Joyetech; Irvine, CA) and a 510-style cartomizer with 1.5 ohms resistance and a dual-heating coil (SmokTech; Smoke Technology Co LTD; Shenzhen China). Cartomizers were filled with $1 \mathrm{ml}$ of e-liquid of the participants' preferred flavor (tobacco or menthol), with $18 \mathrm{mg} / \mathrm{ml}$ of nicotine and a $70: 30 \%$ propylene glycol:vegetable 
glycerin ratio. This combination of device and e-liquid features is capable of delivering pharmacologically active doses of nicotine to both ECIG-experienced and ECIG-naïve users (Spindle et al., 2015b; Hiler et al., 2015).

ECIG topography devices. The eTop and eTop 2.0 continuously monitor, digitize, and record the instantaneous flow rate through an ECIG. Based on the recorded signal, the devices compute the start and end time, and volume of every puff. A puff is detected whenever the flow rate exceeds a user-input threshold (which can be as low as $2 \mathrm{ml} / \mathrm{sec}$ ) for a duration greater than a user-input minimum (e.g. $0.3 \mathrm{sec}$ ). The volume of a puff is computed by numerical integration of the flow rate versus time record of the puff using the trapezoidal rule. Based on the start and end time of every puff, the total number of puffs detected, and the volume of each puff detected, the average puff duration, interpuff interval, and puff volume are computed. Data filtering is applied to the raw flow rate signal. Non-zero flow rates occurring over a duration that is less than the user-input minimum are assigned a value of zero. If two or more adjacent puffs are separated in time by less than a user-input threshold $(0.3 \mathrm{sec})$, they are treated as a single continuous puff.

Video equipment. A Canon Vixia HF R42 (Canon USA, Inc.; Melville, NY) was used to record ECIG use within all conditions. This camera model was chosen based on its video quality, Wi-Fi capabilities, and size. The DIGIC DV 4 Image Processor improves noise-reduction in an image and image clarity in poorly light rooms. Additionally, the small size of the camera may reduce potential effects of observation on smoking behavior. The video data were imported to Adobe Premier Pro 2015 (Adobe Systems, Inc.; San Jose, CA), and analyzed using frame-byframe time analysis. These methods were used in a similar study comparing cigarette topography devices and natural observation (Blank et al., 2009). 


\section{Primary Outcome Measures}

Puff topography. Puff topography variables, as measured by the ECIG topography devices, included puff number (puff count per cigarette), duration (measured in sec), volume (measured in $\mathrm{ml}$ ), IPI (measured in sec), and flow rate (measured in $\mathrm{ml} / \mathrm{sec}$ ). These devices generate a puff at a flow rate greater than $2 \mathrm{ml} / \mathrm{sec}$; thus, the start of a puff is registered when the flow rate reaches $2 \mathrm{ml} / \mathrm{sec}$ and ends when the flow rates returns below $2 \mathrm{ml} / \mathrm{sec}$. Video recordings were used to measure puff number, duration, and IPI, but could not capture puff volume or flow rate. However, puff duration and volume are highly correlated measures (Evans et al., 2003; Gust et al., 1983), and puff duration measurement via video recordings has been used successfully in the past to demonstrate well-established smoking behaviors (Blank et al., 2009; Frederiksen et al., 1977).

Before choosing the final operational definitions for ECIG puffing behaviors, data from several pilot subjects were scored. A puff was counted each time the ECIG (eTop 2.0 and video conditions) or mouthpiece (eTop) was brought to the user's lips, and number was the total number of puffs $>300$ milliseconds within an ECIG bout. Puff duration was defined as the time from the onset to the offset of a single puff, while IPI was defined as the time from the offset of one puff to the onset of the next puff. For these latter two puff topography variables, two different operational definitions were considered: "lip" definition and "light" definition. These definitions differed by the frame (i.e., akin to a still image) chosen for puff onset, as well as that chosen for puff offset. The "lip" definition used the first frame in which the lips were enclosed around an ECIG or topography mouthpiece as puff onset, and the last frame in which the lips were enclosed around the ECIG or mouthpiece as puff offset (i.e., the frame immediately prior to that showing removal of the ECIG/mouthpiece). A similar lip-based definition has been used for 
other video-scored topography for cigarettes (Blank et al., 2009) and ECIGs (Farsalinos et al., 2013; Nides, Leischow, \& Rabinowitz, 2015; St. Helen et al., 2016). The "light" definition used the first frame in which the LED light on the ECIG battery was glowing (indicating that the button had been pressed to active the atomizer) for puff onset, and the last frame in which the LED light remained glowing for puff offset (i.e., the frame immediately prior to that showing that the LED light was no longer glowing). The data captured using video recordings were scored by two independent raters and then compared for reliability (as in Blank et al., 2009; Frederiksen et al., 1977; Lichtenstein \& Antonuccio, 1981), with a minimum cutoff of $r \geq 0.90$.

Acceptability questionnaire. An acceptability questionnaire (Appendix F) was administered to assess participants' subjective experience of how the measurement method used "altered smoking behavior," "made smoking less likely," "reduced smoking enjoyment," "affected the taste of the cigarettes," "made smoking more difficult," and "increased awareness of how much was smoked" (Blank et al., 2009). All items were presented as a VAS with scores that range from 0 to 100 . This set of questions has been used in previous work that involved comparison of methods to measure cigarette topography (Blank et al., 2009) and ECIG topography (Spindle et al., 2015a).

\section{Secondary Outcome Measures}

Hughes and Hatsukami questionnaire. The Hughes and Hatsukami (1986) questionnaire (Appendix G) is a measure of nicotine/tobacco withdrawal symptoms with 11 items: "Urges to smoke", "Irritability/frustration/anger”, “Anxious", "Difficulty concentrating”, Restlessness", "Hunger”, Impatient”, “Craving a cigarette/nicotine”, “Drowsiness”, "Depression/feeling blue", and "Desire for sweets". Participants were shown the word or phrase centered above a horizontal line serving as a visual analog scale (VAS). The left end of the line 
will show the phrase "not at all" (score $=0$ ), and the right end will show the phrase "extremely" $($ score $=100)$. Participants moved the cursor to any point of the line and clicked to create a vertical mark, which could be moved before the participant continued to the next question. Each score was expressed as a percentage of the total line length from the left end to the vertical mark. Internal consistency for this measurement is not assessed, however, the items are known to be valid and reliable indicators of withdrawal symptoms (Hughes \& Hatsukami, 1986; Hughes, 2007). This questionnaire is commonly used assess withdrawal symptoms in cigarette smokers (Blank et al., 2009; Nides et al., 2014; Spindle et al., 2015a; Wagener et al., 2014).

Tiffany-Drobes Questionnaire of Smoking Urges (QSU): Brief Form. The TiffanyDrobes QSU: Brief Form (Appendix H; Cox et al., 2001; Tiffany \& Drobes, 1991) consists of 10 Likert-scale items measuring multidimensional features of nicotine/tobacco cravings. Statements (e.g., "All I want right now is a cigarette"; "I am going to smoke as soon as possible") will be presented above seven boxes, with the leftmost labeled "strongly disagree" (score $=0)$ and rightmost labeled "strongly agree" (score =6). Participants moved the cursor to select one box, which could be adjusted before continuing to the next item. Statements for ECIG-experienced participants were adapted by replacing "cigarette" and "smoke" with "ECIG" and "vape", respectively. Items were collapsed into two factors previously defined by factor analysis: intention to smoke and anticipation of relief from withdrawal. The QSU has demonstrated high reliability (Cronbach's alpha $=0.97$; Cox et al., 2001) and internal consistency within each of the two factors (Cronbach's alpha $=0.96,0.92$; Cox et al., 2001). The QSU is a common measure of nicotine/tobacco withdrawal symptoms (Blank et al., 2009; Blank et al, 2011; Norton et al., 2014; Vansickel \& Eissenberg, 2013). 
Direct Effects of Nicotine Scale (DENS). The DENS (Appendix I; Evans, Blank, Sams, Weaver, \& Eissenberg, 2006) consists of 10 VAS items to assess the severity of nicotineassociated side effects: "nauseous," "dizzy," "lightheaded," "nervous," "sweaty," "headache," "excessive salivation," "heart pounding," "confused," and "weak."

Direct Effects of ECIG Use. The Direct Effects of ECIG Use (Appendix J; Foulds et al., 1992; Pickworth, Bunker, \& Henningfield, 1994) consists of 9 VAS items to assess effects commonly reported with cigarette smoking, but items are modified to ask about vaping (e.g. "Was the ECIG satisfying?" and "Did the ECIG help you concentrate?") (Blank et al., 2011; Spindle et al., 2015a; Vansickel et al., 2010).

Physiological measures. Heart rate and blood pressure were measured continuously throughout each session (Noninvasive Patient Monitor model 506 NP3, Criticare Systems, Inc., Waukesha, WI). Data were collected every $20 \mathrm{sec}$ for heart rate and every $5 \mathrm{~min}$ for blood pressure, and then transferred to a computer. Data for heart rate were averaged into 5-min bins to create a single value pre- and post-vaping for each ECIG bout. The purpose for measurement of these physiological parameters was twofold. First, both heart rate and blood pressure are indicative of exposure to nicotine (Jolma, Samson, Klewer, Donnerstein, \& Goldberg, 2002; Omvik, 1996). Second, heart rate and blood pressure were used to monitor participant safety, and a medical monitor was contacted if a participant's vital signs fell out of a predetermined range (see subsection Participant Safety and Rights). These materials and methods for collected physiological data have been used in similar work (Blank et al., 2009; Breland et al., 2002; Evans et al., 2006; Spindle et al., 2015a). 


\section{Participant Safety and Rights}

Participants' safety and rights were assured through an IRB-approved protocol enacted by trained laboratory staff. Participants were made aware of the Office of Research Integrity and Compliance and the fact that they could contact this office with questions about their rights as participants. Although acute use of an ECIG was expected to incur no adverse events, individuals were informed of the potential risks. For example, participants were informed of the ingredients of the e-liquid in case they have any known allergies to such ingredients. Participants were also warned that they may experience aversive withdrawal symptoms from tobacco abstinence such as irritability, anxiety, and restlessness (Hughes \& Hatsukami, 1986; Rubinstein et al., 2009). These effects may cause discomfort; however, they are not medically dangerous. To ensure safety during ECIG use, physiological measures were monitored continuously. A medical monitor was contacted regarding participant safety if heart rate falls out of the range of 50 to 110 bpm, systolic blood pressure out of the range of 90 to 150, and diastolic pressure out of the range of 60 to 100 . Confidentiality was assured by using coded identity numbers for participant data and storing data in locked rooms and on password protected computers.

\section{Data Preparation and Analysis}

Data Preparation. Prior to data analyses, puff topography data collected via the computerized devices were cleaned by an automated procedure. First, all consecutive puffs separated by less than $300 \mathrm{~ms}$ were combined into a single puff. Next, any remaining single puffs shorter than 300 ms were considered artifacts and thus deleted (as in Spindle et al., 2016). For puff topography data collected via video recordings, this cleanup procedure was manually applied to the values averaged between the two independent raters. Puff topography values within each bout were averaged across puffs to create a single value for puff duration, IPI, puff 
volume, and flow rate (Blank et al., 2009; Spindle et al., 2016). Thus, three values (one for directed and two for $a d$ lib) for these topography variables were produced for each measurement method. Heart rate values were averaged into 5-min bins to create a single value for pre- and post- for each bout (Vansickel et al., 2012; Vansickel et al., 2010).

Data Analyses. Due to the small sample sizes for both groups ( $\mathrm{n}=7$ and 5 for ECIGexperienced and -naïve users, respectively), descriptive statistics and planned comparisons were conducted. Comparisons were chosen based on a combination of published literature suggesting a reliable effect and/or known effect sizes for a given outcome measure. Puff number, duration, and IPI were compared between the measurement methods (eTop, eTop 2.0, and video) using paired samples t-tests. The outcome measures of puff volume and flow rate were not included in these analyses because these topography parameters are not able to be measured by video alone. Puff duration was also compared between ECIG-experienced and ECIG-naïve participants using an independent samples t-test (Farsalinos et al., 2013, Lopez et al., 2016; Ramôa et al., 2015). Select subjective and physiological outcomes were compared between timepoints using paired samples t-tests. The subjective items chosen included "Urges," "Craving”, and "Irritability/Frustration/Anger," from the Hughes-Hatsukami questionnaire (Spindle et al., 2016; Vansickel et al., 2010; Vansickel et al., 2012). Also analyzed were Factor 1 and Factor 2 scores of the Tiffany-Drobes QSU (St. Helen et al., 2016; Vansickel et al., 2012; Vansickel et al., 2010), as well as the items "Satisfying," "Pleasant," and "Tastes Good" for the Direct Effects of ECIG Use (Spindle et al., 2016; Vansickel et al., 2012; Vansickel et al., 2010). Heart rate was the only physiological outcome analyzed (Nides et al., 2014; Vansickel et al., 2012; Vaniskcel et al., 2010). All subjective and physiological items were compared between baseline and post-directed bout, as well as between baseline and the first post-ad lib bout. Previous work has demonstrated 
differences between these timepoints for ECIG-related withdrawal suppression (Dawkins \& Cocoran, 2014; Spindle et al., 2016; St. Helen et al., 2016), and increased ratings of product effects (Spindle et al., 2016; Vansickel et al., 2010; Vansickel et al., 2013).

To correct for multiple comparisons, the False Discovery Rate (FDR) procedure was used (Benjamini \& Hochberg, 1995). This procedure reduces the likelihood of making a Type I error by controlling for the expected proportion of false positives out of all rejected null hypotheses. The FDR procedure was chosen because it provides increased power to detect significant differences as compared to more classical approaches such as the Bonferroni correction, thus reducing the likelihood of a Type II error (Benjamini \& Hochberg, 1995). The FDR procedure involves the ranking of all statistical tests followed by the determination of a new, individual critical value for each test. Thus, the FDR procedure avoids the problem of ambiguity in defining a "family" of statistical tests. Note that all t-tests observed to be significant remained significant after applying the FDR.

The Pearson Correlation Coefficient $(r)(p$ 's $<.05)$ was used for all correlation analyses described below except interrater reliability for puff number. This latter comparison was made using an Intraclass Correlation (ICC; Shrout \& Fleiss, 1979), which assesses absolute agreement between raters. Interrater reliability was assessed by correlating puff number, duration, and IPI for each bout for both the lip and light definition. A minimum cutoff of $r \geq .90$ was used to determine if the two raters were reliable. To determine the relationship between the video and computerized device methods, video scores of puffing via computerized device (eTop or eTop 2.0) or naturally (video) were correlated with scores generated by each computerized device (eTop or eTop 2.0). These correlations were conducted for both the lip and light definitions of 
puff topography derived from the video recordings. To assess reliability of each measurement method, puff topography for the two ad lib bouts within a session were correlated. 


\section{Chapter 3 - Results}

\section{Demographics}

Table 1 displays demographic characteristics for the full sample, as well as for ECIGexperienced and ECIG-naïve participants separately. All participants were male and nonHispanic, and the large majority were White with at least a high school degree. Scores on the respective dependence scale suggested that ECIG-experienced participants were moderately dependent, and ECIG-naïve participants were low to moderately dependent, on their product of choice. Importantly, groups did not differ significantly on age, $t(10)=0.26, p>.05$, years of education, $t(10)=-1.13, p>.05$, or racial category, $\mathrm{x}^{2}(1)=0.07, p>.05$. Statistical tests were not conducted for gender or ethnic category because all participants were male and nonHispanic.

\section{Interrater Reliability}

Table 2 shows that while all topography values were correlated significantly between raters (all p's $<.05$ ), the criterion of $r \geq .90$ was not met for two values using the lip definition and for three values using the light definition. Overall, a higher number of puffs were identified using the lip definition than the light definition. For the directed bout (collapsed across group and device), which was set at 10 puffs, the average $( \pm \mathrm{SD})$ number of puffs counted using the lip definition was $10.0 \pm 0.42($ range $=9-11 ; \operatorname{mode}=10 ;$ median $=10)$ and $10.2 \pm 0.52($ range $=9$ $12 ;$ mode $=10 ;$ median $=10$ ) for the two raters, respectively. For this same bout (collapsed across group and device), the average number of puffs counted using the light definition was 5.7 $\pm 3.8($ range $=0-10 ;$ mode $=10 ;$ median $=6)$ and $7.6 \pm 3.3($ range $=0-11 ;$ mode $=10 ;$ median $=$ 9) for the two raters, respectively. This same pattern was observed for the ad lib bouts, with the lip definition identifying more puffs than the light definition for the same puffing bout. 


\section{Effects of Measurement Method}

Table 3 displays descriptive statistics for all topography variables for each measurement method, and correlations coefficients for comparisons between measurement methods, collapsed across group and bout. All comparisons that included data from the video condition were based on the lip definition, as this definition was assumed to more accurately reflect ECIG puffing based on the descriptive statistics for the directed bout. No significant differences between measurement methods were observed (all $p$ 's $>0.05$ ).

Correlation coefficients for comparisons between data collected via computerized topography devices (i.e., eTop and eTop 2.0 conditions) and via video when no topography device was used (i.e, natural observation condition) are displayed in Table 4. For puff duration, correlations were largely significant between the computerized topography devices and video methods (most $r$ 's $\geq 0.26, p$ 's $<0.05$ ). For puff number and IPI, however, only nine and eight of 24 possible comparisons attained significance (most $r$ 's $<0.42 ; p$ 's $>0.05$ ). Overall, of the 36 comparisons made using each definition, $58.3 \%$ were observed to be significant for the lip definition and $44.4 \%$ were observed to be significant for the light definition. Also notable is that $5.6 \%$ of puffs identified by the eTop and $4.8 \%$ of puffs identified by the eTop 2.0 were not identified by video alone when the lip definition was used. In contrast, $37.6 \%$ of puffs identified by the eTop and $33.3 \%$ of puffs identified by the eTop 2.0 were not identified by video alone when the light definition was used.

Table 5 displays correlations between data collected by computerized topography devices (i.e., eTop and eTop 2.0) and by video recordings of computerized topography device use (i.e., videos of eTop and eTop 2.0). Correlation coefficients attained significance for all comparisons for puff duration ( $r$ 's $>0.47, p$ 's $<.01)$, and for most comparisons for IPI (most $r$ 's $>0.35, p$ 's $>$ 
$.05)$, for both operational definitions. For puff number, however, only nine of 24 possible comparisons were observed to be significant (most $r$ 's $<0.88, p$ 's $>0.05$ ).

There was a significant correlation between the $a d$ lib bouts within each measurement method for puff duration for the eTop $2.0(r=.46, p<.01)$, eTop $(r=.59, p<.01)$, and video using the lip definition $(r=.56, p<.01)$ and light definition $(r=.49, p<.01)$. There was a significant correlation between the ad lib bouts within each measurement for puff number for the eTop $2.0(r=0.83, p<0.01)$, eTop $(r=0.95, p<0.01)$, and video using the lip definition $(r=$ 0.95, $p<0.01)$, and light definition $(r=0.87, p<0.01)$. For IPI, there was a significant correlation between the $a d$ lib bouts within each measurement for the eTop $2.0(r=0.54, p<$ $0.01)$, and video using the lip definition $(r=0.52, p<0.01)$ and light definition $(r=0.34, p<$ $0.05)$, but not for the eTop $(r=0.02, p>0.05)$.

\section{Effects of ECIG-Experience}

Table 6 shows means ( \pm SEMs) for all topography outcomes for group by bout. An independent samples t-test revealed that puff duration did not differ significantly between groups; collapsed across device and bout, the average puff duration for ECIG-experienced cigarette smokers was $3.68 \pm 0.49 \mathrm{sec}$ and for ECIG-naïve users was $4.05 \pm 0.89 \mathrm{sec}(t(65)=$ $1.08, p>.05)$

\section{Acceptability}

Table 7 displays the means and standard deviations for acceptability questionnaire items for each device, separated by group. No comparisons were conducted for any of these items.

\section{Hughes-Hatsukami Questionnaire}

Table 8 displays means and standard errors for the selected subjective and physiological outcomes at baseline, post-directed bout, and post-ad lib 1. For the Hughes-Hatsukami item "Urges", significant differences were observed from baseline to post-directed bout, $t(35)=4.33$, 
$p<.001$, and from baseline to post- $a d$ lib $1, t(35)=5.94, p<.001$. As is apparent from the table, scores for this item decreased significantly from baseline to post-ECIG puffing at each timepoint. Similarly, for "Irritability/Frustration/Anger" scores were also decreased significantly from baseline to post-directed, $t(35)=4.11, p=.001$, and from baseline to post-ad lib $1, t(35)=4.37$, $p<.001$. Finally, scores for "Craving" were significantly lower at post-directed, $t(35)=5.46, p<$ .001 , and post-ad lib $1, t(35)=5.86, p<.001$, timepoints relative to baseline.

\section{Tiffany-Drobes QSU}

For the Tiffany-Drobes QSU, a significant difference in Factor 1 scores (possible range 0 - 30) between baseline and post-directed bout, $t(35)=5.93, p<.001$, as well as between baseline and post-ad lib $1, t(35)=6.00, p<.001$, was observed. Similar findings were revealed for Factor 2 (possible range $0-24$ ) between baseline and post-directed bout, $t(35)=4.31, p<.001$, and between baseline and post- $a d$ lib $1, t(35)=4.87, p<.001$. For both Factor 1 and Factor 2 , ratings were higher at baseline than the post-ECIG puffing timepoints.

\section{Direct Effects of ECIG Use}

For the measure Direct Effects of ECIG Use, ratings of "Satisfying" were significantly lower at baseline than at the post-directed, $t(35)=-5.27, p<.001$, and post-ad lib $1, t(35)=-$ $5.27, p<.001$, timepoints. Significantly lower ratings of "Pleasant" at baseline, relative to postdirected, $t(35)=-4.88, p<.001$, and post-ad lib 1, t(35) $=-4.72, p<.001$, timepoints was also observed. Additionally, ratings of "Taste Good" were significantly different between baseline and post-directed, $t(35)=-2.98, p<.01$, and from baseline to post-ad lib $1, t(35)=-3.39, p<.01$, with lower scores at baseline than the post-ECIG puffing timepoints. 


\section{Heart Rate}

Heart rate increased significantly from baseline to post-directed bout, $t(32)=-5.48, p<$ .001 , as well as from baseline to post-ad lib $1, t(30)=-2.61, \mathrm{p}<.05$. 


\section{Chapter 4 - Discussion}

Puff topography offers an objective measure of nicotine self-administration in humans.

For instance, this measure has been instrumental in predicting nicotine and toxicant delivered from cigarettes to the user (Sutton et al., 1982; Zacny et al., 1987), as well as how user behavior can change in response to differences in cigarette characteristics (Herning et al., 1981; Zacny \& Stitzer, 1988). Consequently, researchers are interested in using puff topography measurement to examine the interaction between user behavior and product characteristics for ECIGs. The ability to measure puff topography is facilitated by the use of computerized devices; however, available commercialized devices were designed to measure cigarette puff topography (Buchhalter \& Eissenberg, 2000; Lee et al., 2003; Blank et al., 2009) and thus may not measure ECIG puffing accurately or reliably. Moreover, devices designed specifically to measure ECIG puff topography, either in the laboratory (Lopez et al., 2016; Ramôa et al., 2015; Spindle et al., 2016) or in the natural environment (Cunningham et al., 2016; Robinson et al., 2015; Robinson et al., 2016), have yet to be tested systematically. The current project was designed to compare the reliability and validity of two different ECIG-based computerized topography devices with natural observation.

\section{Video-Based Topography Measurement}

Two different operational definitions, one lip-based and one light-based, for puff topography outcomes were considered for the natural observation (i.e., video-alone) condition. The reliability criterion was met for more lip-based than light-based scores ( 7 versus 6 , respectively), and raters' number of puffs scored for each bout using the lip-based definition more closely aligned with the number of puffs set for the directed bout (e.g., 10 puffs). Additionally, when puff topography scores were compared between those derived from the 
computerized devices (i.e., eTop and eTop 2.0) and those derived from video recordings of the devices in use, use of the lip-based definition resulted in less missing data. For example, for the directed bout, the lip-based definition missed $1.5 \%$ of puffs scored by the eTop 2.0 and the lightbased definition missed $21.2 \%$ of these puffs. Similarly, for the directed bout, the lip-based definition was missing $3.2 \%$ of puffs scored by the eTop and the light-based definition was missing $38.6 \%$ of these puffs. The relatively large amount of missing data based on the light definition may be due to several factors. First, participants may have pressed the button to activate the atomizer as they were lifting the ECIG to their lips, and before the ECIG was within the view of the video camera. Second, participants may have held their ECIG in such a way that the button was facing away from the camera lens. Finally, participants may have covered the button entirely with their finger. Instructions to participants on how to use their ECIG might resolve these issues, but of course would interfere with natural puffing behavior. Consequently, use of the lip-based definition likely offers a more accurate measure of ECIG puff topography than light-based measures.

\section{Comparisons of Topography Measurement Methods}

Puff number, duration, and IPI did not differ significantly between measurement methods, similar to what has been reported when computerized devices are compared to natural observation for measurement of cigarette smoking topography (Blank et al., 2009). While this finding may imply that all three measurement methods were capturing topography similarly, it is also possible that the sample size was too small to detect meaningful differences between the measurement methods. The relatively small sample size may also have influenced the observed correlations between topography as measured via the computerized devices versus that measured via natural observation methods. Most scores for puff duration, but not number or IPI, were 
significantly correlated between methods when examined as a function of group and bout. These differences may be explained by either the manner in which the devices measure topography or the manner in which users puff on an ECIG when using the devices. The former factor may involve instances of "double puffing," in which an individual takes multiple short puffs in quick succession without fully removing the ECIG or eTop mouthpiece from their lips. In these cases, video-based measurement may identify a single puff while computerized device-based measurement may identify more than one puff. That is, the device may be more sensitive to changes in pressure that occur when users change their pattern of inhalation while the ECIG is in their mouth. Consequently, puff duration and IPI measures will be affected. At least based on this current study, the behavior of "double puffing" appears to occur more often for ECIG puffing than cigarette puffing (Blank et al., 2009). It is also possible that the automated clean-up procedure used to identify and eliminate artifacts generated by the computerized topography devices may have affected topography indices. Regarding the latter issue, users may of course simply puff differently when they use a computerized topography device versus when they puff directly from the ECIG. One of the computerized topography devices relies on an additional mouthpiece (i.e., the eTop) and both devices rely on plastic tubing to measure topography. These device features may have influenced the manner in which an ECIG is held and/or the manner in which the ECIG is placed in the mouth. Future work will need to include larger sample sizes to examine differences between these topography outcomes, as well as between puff volumes and flow rates for the eTop 2.0 and eTop computerized devices.

Cross-study comparisons suggest that the average topography scores observed here do not correspond to those observed in other work, even when participants take 10 puffs from the same ECIG model (e.g., e-GO battery, 510 cartomizer) using the eTop device. For instance, 
longer average puff durations (4.51 - $4.97 \mathrm{sec})$, larger average puff volumes (114.7 - $124.6 \mathrm{ml})$, and higher average flow rates $(23.3-27.78 \mathrm{ml} / \mathrm{sec})$ have been reported for ECIG-experienced users (Ramôa et al., 2015; Spindle et al., 2016). Similarly, shorter average puff durations (2.85 sec) and smaller average puff volumes $(70.2 \mathrm{ml})$ have been reported for ECIG-naïve cigarette smokers (Lopez et al., 2016). In this other work, however, ECIG-experienced users reported use of a higher nicotine concentration $(18.9 \mathrm{mg} / \mathrm{ml}-19.8 \mathrm{mg} / \mathrm{ml})$ and less volume of ECIG liquid per day $(2.0-2.7 \mathrm{ml})$, while ECIG-naïve cigarette smokers reported smoking for longer (average = 10 years), as compared to participants in the current study (Lopez et al., 2016; Ramôa et al., 2015; Spindle et al., 2016). These participant characteristics may account for some of the differences noted here.

Overall, ECIG puff topography was measured by the computerized devices precisely as was measured by the video recordings of use of these same computerized devices. Specifically, correlations between these measurements as a function of group and bout were largely significant ( $r$ 's ranged from 0.47 to $1.0, p$ 's $<0.05$ ). Still, some correlations for puff number, particularly for ECIG-naïve participants, were not significant. Importantly, all methods measured topography reliably, as evidenced by the significant correlations for most topography indices between $a d$ lib bouts within a condition. Still, these correlation coefficients (r) were no higher than 0.59 , and lower than what has been reported for cigarette topography $(r$ 's $\geq 0.69$, Blank et al., 2009). Notable is that cigarette puffing topography for dependent cigarette smokers has shown to be a well-established behavior in that puffing is consistent within and across cigarettes (Lee et al., 2003; Perkins, Karelitz, Giedgowd, and Conklin, 2012). In the current study, ECIGnaïve cigarette smokers reported no more than 5 ECIG uses in their lifetime $(M=2.6, S D=$ 1.95), and thus were puffing on an unfamiliar product. The ECIG experienced users reported use 
of their ECIG for an average of only 1.96 years, and also may have been puffing on an ECIG device different from their usual model. Specifically, four of seven ECIG-experienced users were using third-generation devices, which are more advanced models than the ECIG model used in this study. Additionally, for the three participants that reported using a second-generation device, that device had a higher power output than the ECIG model used in this study. Finally, all of the ECIG users reported a preference for sweet or fruit flavored (e.g., strawberry vanilla, custard, sweet tart) liquid, while the liquid used in the current study was unflavored. These differences in ECIG device and liquid features may have influenced natural puffing among ECIG-experienced users.

\section{ECIG Experience-Induced Effects}

Average puff duration did not differ significantly between ECIG-experienced users (3.68 sec) and ECIG-naïve cigarette smokers $(4.05 \mathrm{sec})$. For the ECIG-experienced users, this observed value is consistent with some literature (e.g., average puff durations 3.5-3.84 sec; Dawkins et al., 2016; Robinson et al., 2015; St Helen et al., 2016), but lower than that reported in other literature (e.g., average puff durations 4.2-5.29 sec; Farsalinos et al., 2013; Ramôa et al., 2015; Spindle et al., 2016). For the ECIG-naïve cigarette smokers, the observed value is notably greater than that reported previously for this population (e.g., average puff durations 2.4-3.0 sec; Farsalinos et al., 2013; Lopez et al., 2016, Norton et al., 2014). Differences between studies may be due to a variety of factors, including the device used to measure topography, the type of ECIG device used, the cigarette or ECIG use history characteristics of the participants, or pre-session nicotine/tobacco abstinence. Regarding this latter factor, participants in this study were required to abstain from all nicotine/tobacco products for $\geq 12$ hours prior to a session. Unfortunately, this requirement could be verified only in the ECIG-naïve cigarette smokers, at least based on the 
biological fluid chosen to detect recent product use. Specifically, expired air CO provides a measure of exposure to tobacco products that are combusted (e.g., cigarettes), but not products that are aerosolized (e.g., ECIGs). The testing of other biological fluids, however, was not possible. Urinary or salivary cotinine, a metabolite of nicotine, has a half-life of approximately 17 hours (Jarvis, Russel, Benowitz, \& Feyerabend, 1988), and thus is not a sensitive measure of short-term cigarette or ECIG abstinence. Nicotine can be measured in blood plasma, and has a half-life of only approximately 2 hours (Benowitz, 2009). Still, the testing of plasma nicotine requires specialized equipment and expertise that was not available for immediate use to confirm abstinence. For these reasons, it is unknown whether the ECIG-experienced users who completed the current study complied with the overnight abstinence requirement. ECIG-experienced users who were nicotine satiated may have puffed differently than if they were nicotine abstinent, as has been demonstrated for cigarette puffing topography as a function of time since last cigarette (Fant, Schuh, \& Stitzer, 1995). Of course, findings may also be due to the relatively small sample size $(n=5)$, and thus outliers. Average puff durations for the ECIG-naïve cigarette smokers included here ranged from $1.70 \mathrm{sec}$ to $6.66 \mathrm{sec}$. It appears that an average puff duration of $6.66 \mathrm{sec}$ is more than double the mean for ECIG-naïve participants in the literature (Farsalinos et al., 2013; Lopez et al., 2016; Norton et al., 2014).

\section{Subjective and Physiological Response}

In this study, ECIG use reliably suppressed a variety of withdrawal symptoms, as has been reported for both ECIG-experienced users and ECIG-naïve cigarette smokers (Dawkins \& Cocoran, 2014; Spindle et al., 2016; Vansickel et al., 2012; Vansickel et al., 2010). Specifically, scores on items such as "Irritability/Frustration/Anger" and "Craving” were decreased significantly from pre- to post-ECIG use. ECIG use also reliably increased ratings on items 
indicative of positive effects of ECIG use (e.g., "satisfying," "pleasant," and "tastes good"), as well as increased heart rate. These effects are also are consistent with what has been reported in the literature for both ECIG-experienced users and ECIG-naïve cigarette smokers (Spindle et al., 2016; Vansickel et al., 20121 Vansickel et al., 2010). This pattern of results may indicate that the ECIG effectively delivered nicotine to the user. Indeed, previous work has shown the delivery of cigarette-like nicotine concentrations with relatively short puffing bouts with the same ECIG device as used in the current study has shown (Lopez et al., 2016; Spindle et al., 2016; Ramôa et al., 2015). Alternatively, this pattern of results may be due to learning, or exposure to cues that are shared between cigarettes and ECIGs. ECIGs and cigarettes may share similar form and function, as well as similar user behaviors such as hand to mouth movements and inhalation and exhalation behaviors, that may serve as similar cues between the two products (King et al., 2016).

\section{Strengths}

Multiple features of the experimental design add validity to the current study as compared to other research using ECIG topography devices. First, the current study employed a rigorous method to validate the topography measurement methods. For example, the current study made comparison between two different topography devices, along with natural puffing observed by video recording. This design has been used to validate cigarette topography measurement methods (Blank et al., 2009), but has not been used in any ECIG topography research. Additionally, the exploration of two definitions for video scored puff topography provide reasoning for the use of the "lip" definition when evaluating topography by this method. Another strength of the current study is the use of both directed and ad lib bouts. Using a standardized, 10-puff directed bout with $30 \mathrm{sec}$ IPIs is common in topography research and 
allows for direct comparisons across studies (Lopez et al., 2016; Ramôa et al., 2015; Spindle et al., 2016). The use of ad lib bouts is also advantageous as it provides insight on ECIG puffing behavior that is more representative of natural or typical use. Finally, a value of the current study was the use of a standardized ECIG across all participants, in attempts to reduce variability associated with different ECIG designs and personal preferences.

\section{Limitations}

Study outcomes may have been affected by several limitations. First, the targeted sample size was not reached due to delays in grant funding and the termination of the funding period before the full sample was completed. The final sample size of 12 is much smaller than the planned size of 40, and thus power to detect differences between variables was reduced. Consequently, Type II error $(\beta)$, or the likelihood of failing to the reject the null hypothesis when it is false (Cohen, 1988), was likely inflated. The observed effect sizes for device comparisons for the primary outcomes, puff number (partial $\eta^{2}=0.06$ ), puff duration (partial $\eta^{2}=0.12$ ), and IPI (partial $\eta^{2}=0.14$ ), were small, and the observed power for these tests ranged from $0.06-$ 0.23. Thus, due to the combination of small effect sizes and a small sample size, the likelihood of making a Type II error was high. Additionally, the likelihood of making a Type I error ( $\alpha$ ) was likely increased due to the many comparisons that were conducted (i.e., 30 t-tests). Type I error is the probability of rejecting the null hypothesis when it is true (Cohen, 1988). In an attempt to control the Type I error rate, the FDR was employed. Specifically, this procedure involves the determination of a new critical value for each statistical test conducted, based on the total number of tests being conducted (Benjamini \& Hochberg, 1995). Still, this approach is not as conservative as others such as the Bonferroni correction. 
A second limitation is the inability to verify abstinence in ECIG-experienced participants, as mentioned previously. Indeed, this challenge has been highlighted recently in work by our laboratory (Blank et al., 2016). For example, differences have been observed between ECIGexperienced users and ECIG-naïve cigarette smokers when $\mathrm{CO}$ and plasma nicotine levels are used to verify product abstinence (Lopez et al., 2016; Ramôa et al., 2015). Specifically, ECIGnaïve cigarette smokers reveal both a low $\mathrm{CO}$ concentration (e.g., $6.7 \mathrm{ppm}$ ) and a low plasma nicotine concentration $(3.3 \mathrm{ng} / \mathrm{ml})$ in response to an overnight abstinence requirement. In contrast, ECIG-experienced users reveal a lower $\mathrm{CO}$ concentration of $3.0 \mathrm{ppm}$, but a higher plasma nicotine concentration of $5.8 \mathrm{ng} / \mathrm{ml}$. Thus, the requirement of abstinence would be met by both groups using the expired air CO measure, but not the plasma nicotine measure. Rather, a plasma nicotine concentration of $5.8 \mathrm{ng} / \mathrm{ml}$ suggests that the ECIG-experienced users were not actually abstinent from nicotine. Thus, the issue of abstinence from ECIG use is a problem that plagues ECIG research at-large, and may contribute to the differences in results between studies.

A third limitation is that results may not generalize to ECIG use in a natural environment, as ECIG use was measured in a laboratory environment. Little is known about natural ECIG puffing behavior, and it is possible that 5-min ad lib bouts are not long enough to simulate a typical ECIG-use session. Particularly, it is difficult to define a "single ECIG use episode", as ECIG-experienced users may use their ECIG constantly throughout the day, as well as use multiple device types (Blank et al., 2016). One study found that multiple ECIG-experienced users engaged in puffing bouts that lasted less than $20 \mathrm{sec}$ and included three or fewer puffs, while other ECIG-experienced users engaged in puffing bouts that were over six min and involved 12 or more puffs (Robinson et al., 2016). Additionally, some ECIG-experienced users grouped multiple puffs together with short IPIs, and separated these groupings by a longer IPI, 
while other ECIG-experienced users spread puffs more evenly across a bout. This pattern is different from that observed for cigarette smoking where a bout (i.e., one cigarette) is easily defined.

A final limitation involved multiple difficulties incurred regarding the measurement of puff topography. First, results from initial participants indicated that the eTop 2.0 device made puffing more difficult, potentially by inhibiting flow rates. Thus, the device needed to be altered (i.e., flow collar was altered to allow more air flow in) to attempt to adjust for this interference with natural puffing. Additionally, calibration procedures of the topography devices were not fully consistent throughout the study, adding the potential for an unexpected source of error into topography measurement. Finally, there were multiple instances in which the topography device was known to be incorrect. For example, during the directed bout (30 sec IPI), there was occasionally a computer lag that caused the IPI to be measured at a shorter duration than $30 \mathrm{sec}$. There was one bout in which puff durations exceeded $100 \mathrm{sec}$, which was obviously an error in measurement. This bout was excluded from data analyses, which has been done in another ECIG topography study when puff durations exceeded $20 \mathrm{sec}$ (Robinson et al., 2016).

\section{Conclusions and Future Directions}

Given the small sample size, it is difficult to draw definitive conclusions from this study. One potential conclusion from this study is the reduction of withdrawal symptoms associated with ECIG use, as this was reliably shown for multiple measures and bouts. However, evaluating measurement method validity and reliability, the main purpose of the study, is difficult under the current conditions. While the topography devices did not differ significantly for puff number, duration, or IPI, the study was potentially underpowered to detect statistically significant differences. Additionally, differences in flow rate and volume were not assessed in this study, 
which may differ between measurement methods. Future research should employ similar methods with a full sample size to evaluate the topography devices in the current study, as well as other methods being used to evaluate ECIG puff topography. Additionally, it is imperative for ECIG puff topography research to include measurements of plasma nicotine levels, in an effort to verify abstinence as well as examine nicotine delivery. Similarly, more research comparing video and topography device measurement should be conducted to determine the consistencies and inconsistencies of these methods, and if the low correlations for specific conditions in this study were a random or replicable finding. Finally, more natural environment topography studies must be conducted to assess how lab paradigms of puffing differ from typical behavior. 


\section{References}

Agboola, S. A., Coleman, T., McNeill, A., \& Leonardi-Bee, J. (2015). Abstinence and relapse amongst smokers who use varenicline in a quit attempt - a pooled analysis of randomized controlled trials. Addiction, 110(7), 1182-1193. doi:10.1111/add.12941.

Aubin, H. J., Bobak, A., Britton, J. R., Oncken, C., Billing, C. B. Jr., Gong, J., Williams, K. E., \& Reeves, K. R. (2008). Varenicline versus transdermal nicotine patch for smoking cessation: results from a randomised open-label trial. Thorax, 63, 717-724. doi: $10.1136 /$ thx.2007.090647.

Ayers, J. W., Ribisl, K. M., Brownstein, J. S. (2011). Tracking the ride in the popularity of electronic nicotine delivery systems (electronic cigarettes) using search query surveillance. American Journal of Preventative Medicine, 40(4), 448-453. doi:10.1016/j.amepre.2010.12.007.

Behar, R. Z., Hua, M., \& Talbot, P. (2015). Puffing topography and nicotine intake of electronic cigarette users. PLoS One, 10(2), e0117222. doi:10.1371/journal.pone.0117222.

Benjamini, Y., \& Hochberg, Y. (1995). Controlling the false discovery rate: a practical and powerful approach to multiple testing. Journal of the Royal Statistical Society, Series B (Methodological), 57, 289-300.

Benowitz, N. L. (2001). Compensatory smoking of low-yield cigarettes. Risks associated with smoking cigarettes with low machine-measured yields of tar and nicotine. Smoking and Tobacco Control Monograph, 13. Bethesda, Maryland: National Cancer Institute.

Benowitz, N. L. (2009). Pharmacology of nicotine: Addiciton, smoking-induced disease, and therapeutics. Annual Review of Pharmacology and Toxicology, 49, 57-71. 
Benowitz, N. L., Hall, S. M., Herning, R. I., Jacob, P. III, Jones, R. T., \& Osman, A. L. (1983). Smokers of low-yield cigarettes do not consume less nicotine. The New England Journal of Medicine, 309(3), 139-142.

Benowitz, N. L., Jacob, P. III, Kozlowski, L. T., and Yu, L. (1986). Influence of smoking fewer cigarettes on exposure to tar, nicotine, and carbon monoxide. New England Journal of Medicine, 315(21), 1310-1313.

Blank, M. D., Breland, A. B., Cobb, C. O., Spidnle, R., Ramôa, C., \& Eissenberg, T. (2016). Clinical laboratory evaluation of electronic cigarettes: Methodological challenges. Tobacco Regulatory Science, 2(4), 426-439.

Blank, M. D., Cobb, C. O., Kilgalen, B., Austin, J., Weaver, M. F., Shihadeh, A., \& Eissenberg, T. (2011). Acute effects of waterpipe tobacco smoking: a double-blind, placebo-control study. Drug and Alcohol Dependence, 116, 102-109. doi:10.1015//j.drugalcdep.2010.11.026.

Blank, M. D., Disharoon, S., \& Eissenberg, T. (2009). Comparison of methods for measurement of smoking behavior: mouthpiece-based computerized devices versus direct observation. Nicotine \& Tobacco Research, 11(7), 896-903. doi:10.1093/ntr/ntp083.

Breland, A. B., Buchhalter, A. R., Evans, S. E., \& Eissenberg, T. (2002). Evaluating acute effects of potential reduced-exposure products for smokers: clinical laboratory methodology. Nicotine \& Tobacco Research, S131-S140. doi:10.1080/1462220021000032780.

Brown, C. J., \& Cheng, J. M. (2014). Electronic cigarettes: product characterization and design considerations. Tobacco Control, 23, ii4-ii10. doi:10.1136/tobaccocontrol-2013-051476. 
Buchhalter, A. R. and Eissenberg, T. (2000). Preliminary evaluation of a novel smoking system: effects on subjective and physiological measures and on smoking behavior. Nicotine and Tobacco Research, 2(1), 39-43.

Cahill, K., Stevens, S., Perera, R., \& Lancaster, T. (2013) Pharmacological interventions for smoking cessation: an overview and network meta-analysis (review). The Cochrane Library, 5, Art.No.:CD009329. doi:10.1002/14651858.CD009329.pub2.

Cassidy, S. (2011, October 26). How electronic cigarettes work. Retrieved February, 2015, from http://science.howstuffworks.com/innovation/everyday-innovations/electroniccigarette.htm.

Centers for Disease Control and Prevention. (2011). Quitting smoking among adults - United States, 2001-2010. Morbidity and Mortality Weekly Report, 60(44), 1513-1519.

Centers for Disease Control and Prevention. (2013). E-cigarette use more than doubles among U.S. middle and high school students from $2011-2012$ (Press Release). Retrieved from http://www.cdc.gov/media/releases/2013/p0905-ecigarette-use.html.

Centers for Disease Control and Prevention. (2014). Current cigarette smoking among adults United States, 2005-2012. Morbidity and Mortality Weekly Report, 63(02), 29-34.

Cobb, C. O., Weaver, M. F., \& Eissenberg, T. (2010). Evaluating the acute effects of oral, noncombustible reduced exposure products marketed to smokers. Tobacco Control, 19(5), 367-373. doi:10.1136/tc2008.028993.

Cohen, J. (1988). Statistical power analysis for the behavior $\left(2^{\text {nd }}\right.$ ed). Orlando, FL: Academic Press. 
Cox, L. S., Tiffany, S. T., \& Christen, A. G. (2001). Evaluation of the brief questionnaire of smoking urges (QSU-brief) in laboratory and clinical settings. Nicotine \& Tobacco Research, 3, 7-16.

Cunningham, A., Slayford, S., Vas, C., Gee. J., Costigan, S., \& Prasad, K. (2016). Development, validation, and application of a device to measure e-cigarette users' puffing topography. Scientific Reports, 6, 35071. doi:10.1038/srep35071.

Davis, B., Dang, M., Kim, J., \& Talbot, P. (2015). Nicotine concentrations in electronic cigarette refill and do-it-yourself fluids. Nicotine \& Tobacco Research, 17(2), 134-141. doi:10.1093/ntr/ntu080.

Dawkins, L., \& Corcoran, O. (2014). Acute electronic cigarette use: nicotine delivery and subjective effects in regular users. Psychopharmacology, 231, 401-407. doi:10.1007/s00213-013-3249-8.

Dawkins, L., Kimber, C. E., Doig, M., Feyerabend, C., \& Cocoran, O. (2016). Self-titration by experienced e-cigarette users: blood nicotine delivery and subjective effects. 233, 29332941.

Djordjevic, M.V., Hoffmann, D., and Hoffmann, I. (1997). Nicotine regulates smoking patterns. Preventive Medicine, 26, 435-440.

Eisenberg, M. J., Filion, K. B., Yavin, D., Bélisle, P., Mottillo, S., Joseph, L., . . Pilote, L. (2008). Pharmacotherapies for smoking cessation: a meta-analysis of randomized controlled trials. Canadian Medical Association Journal, 179(2), 135-144. doi:10.1503/cmaj.070256.

Eissenberg T. (2014) Acute effects of electronic cigarettes in adults: nicotine delivery and abuse liability. In S. Krishnan-Sarin (Chair), Electronic Cigarettes: current state of the 
knowledge and future research. Symposium conducted at the 20th Annual Meeting of the Society for Research on Nicotine and Tobacco, Seattle, WA, February.

Eissenberg, T., Griffiths, R. R., \& Stitzer, M. L. (1996). Mecamylamine does not precipitate withdrawal in cigarette smokers. Psychopharmacology, 127, 328-336.

Etter, J. F. (2012). The electronic cigarette: an alternative to tobacco?. Jean-Francois Etter, Geneva, Switzerland.

Evans, S. E., Blank, M., Sams, C., Weaver, M. F., \& Eissenberg, T. (2006). Transdermal nicotine-induced tobacco abstinence symptom suppression: nicotine dose and smokers' gender. Experimental and Clinical Psychopharmacology, 14(2), 121-135.

Evans, S. E., Buchhalter, A., Kleykamp, B., and Eissenberg, T. (2003). Ambulatory puff topography measurement: a validation study. Poster presented at the 9th annual meeting of the Society for Research on Nicotine and Tobacco, New Orleans, LA, February.

Evans, S. E., \& Hoffman, A. C. (2014). Electronic cigarettes: abuse liability, topography, and subjective effects. Tobacco Control, 23, ii23-9929. doi:10.1135/tobaccocontrol-2013051489.

Family Smoking Prevention and Tobacco Control Act of 2009. Public Law 111-31. 123 Stat. 1780.

Fant, R. V., Schuh, K. J., \& Stitzer, M. L. (1995). Response to smoking as a function of prior smoking amounts. Psychopharmacology, 119, 385-390.

Farsalinos, K. E., Romagna, G., Tsiapras, D., Kyrzopoulos, S., Voudris, V. (2013). Evaluation of electronic cigarette user (vaping) topography and estimation of liquid consumption: implications for research protocol standard definition and for public health authorities' 
regulation. International Journal of Environmental Research and Public Health, 10, 2500-2514. doi:10.3390/ijerph10062500.

Farsalinos, K. E., Spyrou, A., Tsimopoulou, K., Stefopoulos, C., Romagna, G., \& Voudris, V. (2014). Nicotine absorption from electronic cigarette use: comparison between first and new-generation devices. Scientific Reports, 4, 4133. doi:10.1038/srep04133.

Fiore M. C., Jaén C. R., Baker T. B., et al. (2008). Treating tobacco use and dependence: 2008 update. Clinical Practice Guideline. Rockville, MD: U.S. Department of Health and Human Services. Public Health Service.

Food and Drug Administration (2012). Harmful and potentially harmful constituents in tobacco products and tobacco smoke; established list (Docket No. FDA-2012-N-0143). Federal Register, 77(64), 20034-20037.

Food and Drug Administration (2014). Electronic cigarettes (e-cigarettes). Retrieved from http://www.fda.gov/NewsEvents/PublicHealthFocus/ucm172906.htm.

Foulds, J., Ramstrom, L., Burke, M., \& Fagerström. (2003). Effects of smokeless tobacco (snus) on smoking and public health in Sweden. Tobacco Control, 12, 349-359.

Foulds, J., Stapleton, J., Feyerabend, C., Vesey, C., Jarvis, M., \& Russell, M. A. (1992). Effect of transdermal nicotine patches on cigarette smoking: a double blind crossover study. Psychopharmacology, 106, 421-427.

Foulds, J., Veldheer, S., Yingst, J., Hrabovsky, S., Wilson, S. J., Nichols, T. T., \& Eissenberg, T. (2015). Development of a questionnaire for assessing dependence on electronic cigarettes among a large sample of ex-smoking e-cigarette users. Nicotine \& Tobacco Research, 17(2), 186-192. doi:10.1093/ntr/ntu204. 
Fraser, D., Kobinsky, K., Smith, S. S., Kramer, J., Theobald, W. E., \& Baker, B. (2014). Five population-based interventions for smoking cessation: a MOST trial. Translational Behavioral Medicine, 4, 382-390. doi:10.1007/s13142-014-0278-8.

Frederiksen, L. W., Miller, P. M., and Peterson, G. L. (1977). Topographical components of smoking behavior. Addictive Behaviors, 2(1), 55-61.

Goniewicz, M. L., Kuma, T., Gawron, M., Knysak, J., \& Kosmider, L. (2013). Nicotine levels in electronic cigarettes. Nicotine \& Tobacco Research, 15(1), 158-166. doi:10.1093/ntr/nts103.

Gonzales, G., Rennard, S. I., Nides, M., Oncken, C., Azoulay, S., Billing, C.B., . . Reeves, K.R. (2006). Varenicline, an a4ß2 nicotinic acetylcholine receptor partial agonist, vs sustainedrelease bupropion and placebo for smoking cessation: a randomized controlled trial. The Journal of the American Medical Association, 296(1), 47-55. doi:10.1001/jama.296.1.47.

Grana, R., Benowitz, N., \& Glantz, S. A. (2014). E-cigarettes a scientific review. Circulation, 129, 1972-1986. doi:10.1161/CIRCULATIONAHA.114.007667.

Gust, S. W., Pickens, R. W., and Pechacek, T. F. (1983). Relation of puff volume to other topographical measures of smoking. Addictive Behaviors, 8(2), 115-119.

Hahn, J., Monakhova, Y.B., Hengen, J., Kohl-Himmelseher, M., Schüller, J., Hahn, H., . . . Lachenmeier, D.W. (2014). Electronic cigarettes: overview of chemical composition and exposure estimation. Tobacco Induced Diseases, 12(1), 23. doi:10.1186/s12971-0140023-6.

Hajek, P., Goniewicz, M. L., Phillips, A., Smith, K. M., West, O., \& McRobbie, H. (2015). Nicotine intake from electronic cigarettes on initial use and after 4 weeks of regular use. Nicotine \& Tobacco Research, 17(2), 175-179. doi:10.1093/ntr/ntu153. 
Hammond, D., Fong, G. T., Cummings, K. M., \& Hyland, A. (2005). Smoking topography, brand switching, and nicotine deliver: results from an in vivo study. Cancer Epidemiology, Biomarkers \& Prevention, 14(6), 1370-1375.

Heatherton, T. F., Kozlowski, L. T., Frecker, R. C., \& Fagerström, K. O. (1991). The Fagerström test for nicotine dependence: a revision of the Fagerström tolerance questionnaire. British Journal of Addiction, 86, 1119 - 1127.

Hecht, S. S., Carmella, S. G., Kotandeniya, D., Pillsbury, M. E., Chen, M., Ransom, B. W. S., . . . Hatsukami, D.K. (2014). Evaluation of toxicant and carcinogen metabolites in the urine of e-cigarette users versus cigarette smokers. Nicotine \& Tobacco Research, 17(6), 704709. doi:10.1093/ntr/ntu218.

Henningfield, J. E., Yingling, J., Griffiths, R. R., and Pickens, R. (1980). An inexpensive portable device for measuring puffing behavior by cigarette smokers. Pharmacology, Biochemistry, and Behavior, 12(5), 811-813.

Herning, R. I., Jones, R. T., Bachman, J., and Mines, A. H. (1981). Puff volume increases when low-nicotine cigarettes are smoked. British Medical Journal, 283(6285), 187-189.

Hiler, M., Kilgalen, B., Breland, A., Lipato, T., \& Eissenberg, T. (2015). Is an electronic cigarette user's plasma nicotine concentration related to liquid nicotine concentration?. Poster presented at the 21 st annual meeting of the Society for Research on Nicotine and Tobacco, Philadelphia, PA, February.

Hughes, J. R. (2007). Effects of abstinence from tobacco: valid symptoms and time course. Nicotine \& Tobacco Research, 9(3), 315-327. doi:10.1080/14622200701188919.

Hughes, J. R., \& Hatsukami, D. (1986). Signs and symptoms of tobacco withdrawal. Archives of General Psychiatry, 43, $289-294$. 
Hua, M., Yip, H., \& Talbot, P. (2013). Mining data on usage of electronic nicotine delivery systems (ENDS) from YouTube videos. Tobacco Control, 22(2), 103-106. doi:10.1136/tobaccocontrol-2011-050226.

International Agency for Research on Cancer. (2007). Reversal of risk after quitting smoking. IARC handbooks of cancer prevention, tobacco control., Vol. 11. IARC, Lyon, France.

Jolma, C. D., Samson, R. A., Klewer, S. E., Donnerstein, R. L., \& Goldberg, S. J. (2002). Acute cardiac effects of nicotine in healthy young adults. Echocardiography, 19, 443-448.

Keppel, G. (1991). Design and analysis: A researcher's handbook. Englewood Cliffs, NJ: Prentice Hall.

King, B. A., Patel, R., Nguyen, K. H., \& Dube, S. R. (2015). Trends in awareness and use of electronic cigarettes among US adults, 2010-2013. Nicotine \& Tobacco Research. 17(2), 219-227. doi:10.1093/ntr/ntu191.

King, A. C., Smith, L. J., Fridberg, D. J., Matthews, A. K., McNamara, P. J., \& Cao, D. (2016). Exposure to electronic nicotine delivery device (ENDS) visual imagery increases smoking urge and desire. Psychology of Addictive Behaviors, 30, 106-112.

Kosmider, L., Sobczak, A., Fik, M., Knysak, J., Zaciera, M., Kurek, J., \& Goniewicz, M. L. (2014a). Carbonyl compounds in electronic cigarette vapors: Effects of nicotine solvent and battery output voltage. Nicotine \& Tobacco Research, 16(10), 1319-1326. doi:10.1093/ntr/ntu078.

Kosmider, L., Sobczak, A., Knysak, J., \& Goniewicz, M.L. (2014b). Effects of solvent and battery output voltage on nicotine levels released from electronic cigarettes. Presented at the 20th annual meeting of the Society for Research on Nicotine and Tobacco, Seattle, WA, February. 
Kozlowski, L. T., O'Connor, R. J., and Sweeney, C. T. (2001). Cigarette design. Risks associated with smoking cigarettes with low machine-measured yields of tar and nicotine. Smoking and Tobacco Control Monograph, 13. Bethesda, Maryland: National Cancer Institute.

Lechner, W. V., Meier, E., Wiener, J. L., Grant, D. M., Gilmore, J., Judah, M. R., .. . Wagener, T. L. (2015). The comparative efficacy of first- versus second-generation electronic cigarettes in reducing symptoms of nicotine withdrawal. Addiction. 110(5), 862-867. doi:10.1111/add.12870.

Lee, P. N. (2013). The effect on health of switching from cigarettes to snus - a review. Regulatory Toxicology and Pharmacology, 66, 1-5.

Lee, E. M., Malson, J. L., Waters, A. J., Moolchan, E. T., and Pickworth, W. B. (2003). Smoking topography: reliability and validity in dependent smokers. Nicotine and Tobacco Research, 5(5), 673-679.

Lichtenstein, E., \& Antonuccio, D.O. (1981). Dimensions of smoking behavior. Addictive Behaviors, 6, 365-367.

Lisko, J. G., Tran, H., Stanfill, S. B., Blount, B. C., \& Watson, C. H. (2015). Chemical composition and evaluation of nicotine, tobacco alkaloids, $\mathrm{pH}$, and selected flavors in ecigarette cartridges and refill solutions. Nicotine \& Tobacco Research, 17(10), 12701278. doi:10.1093/ntr/ntu279.

Lopez, A. A., Hiler, M. H., Soule, E. K., Ramôa, C. P., Karaoghlanian, N. V., Lipato, T., .. . Eissenberg, T. (2016). Effects of electronic cigarette liquid nicotine concentration on plasma nicotine and puff topography in tobacco cigarette smokers: a preliminary report. Nicotine \& Tobacco Research, 18(5), 720-723. 
Luo, J., Ye, W., Zendehdel, K., Adami, J., Adami, H.O., Boffetta, P., \& Nyrén. (2007). Oral use of Swedish moist snuff (snus) and risk for cancer of the mouth, lung, and pancreas in male construction workers: a retrospective cohort study. Lancet, 369, 2015-2020. doi: 10.1016/S0140-6736(07)60678-3.

McCarthy, D. E., Piasecki, T. M., Lawrence, D. L., Jorenby, D. E., Shiffman, S., Fiore, M. C., \& Baker, T. B. (2008). A randomized controlled clinical trial of bupropion SR and individual smoking cessation counseling. Nicotine \& Tobacco Research, 10(4), 717-729. doi: $10.1080 / 1462220801968343$.

McMillen, R. C., Gottlieb, M. A., Whitmore Shaefer, R. M., Winickoff, J. P., \& Klein, J. D. (2014). Trends in electronic cigarette use among U.S. adults: use is increasing in both smokers and nonsmokers. Nicotine \& Tobacco Research, 17(10), 1195-1202. doi:10.1093/ntr/ntu213.

Messer, K., Trinidad, D. R., Al-Dalaimy, W. K., \& Pierce, J. P. (2008). Smoking cessation rates in the United States: A comparison of young adult and older smokers. American Journal of Public Health, 98, 317-322.

Nides, M. A., Leischow, S. J., Bhatter, M., Simmons, M. (2014). Nicotine blood levels and short-term smoking reduction with an electronic nicotine delivery system. American Journal of Health Behavior, 38(2), 265-274. http://dx.doi.org/10.5993/AJHB.38.2.12.

Nides, M. A., Leischow, S. J., \& Rabinowitz, J. D. (2015). Usage patterns, blood nicotine and cotinine levels, and puff topography among exclusive users of tank type electronic nicotine delivery systems (ENDS). Poster presented at the 21 st annual meeting of the Society for Research on Nicotine and Tobacco, Philadelphia, PA, February. 
Norberg, M., Malmberg, G., Ng, N., \& Broström, G. (2011). Who is using snus? - Time trends, socioeconomic and geographic characteristics of snus users in the ageing Swedish population. BMC Public Health, 11, 929. http://www.biomedcentral.com/14712458/11/929.

Norberg, M., Malmberg, G., Ng, N., \& Broström, G. (2015). Use of moist smokeless tobacco (snus) and the risk of development of alcohol dependence: a cohort study in a middleaged population in Sweden. Drug and Alcohol Dependence, 149, 151-157. http://dx.doi.org/10.1016/j.drugalcdep.2015.01.042.

Norton, K. J., June, K. M., \& O’Connor, R. J. (2014). Initial puffing behaviors and subjective Reponses differ between an electronic nicotine delivery system and traditional cigarettes. Tobacco Induced Diseases, 12, 1-8.

Omvik, P. (1996). How smoking affects blood pressure. Blood Pressure, 5(2), 71-77.

Pauly, J., Li, Q., \& Barry, M. B. (2007). Tobacco-free electronic cigarettes and cigars deliver nicotine and generate concern. Tobacco Control, 16(5), 357. doi:10.1136/tc.2006.019687.

Perkins, K. A., Karelitz, J. L., Giedgowd, G. E., \& Conklin, C. A. (2012). The reliability of puff topography and subjective responses during ad lib smoking of a single cigarette. Nicotine \& Tobacco Research, 14(4), 490-494.

Pickworth, W. B., Bunker, E. B., \& Henningfield, J. E. (1994). Transdermal nicotine: reduction of smoking with minimal abuse liability. Psychopharmacology, 115(1-2), 9-14.

Puustinen, P., Olkkonen, H., Kolonen, S., and Tuomisto, J. (1987). Microcomputer-aided measurement of puff parameters during smoking of low- and medium-tar cigarettes. Scandinavian Journal of Clinical Laboratory Investigation, 47(7), 655-660. 
Ramôa, C. P., Hiler, M. M., Spindle, T. R., Lopez, A. A., Karaoghlanian, N., Lipato, T., . . Eissenberg, T. (2015). Electronic cigarette nicotine delivery can exceed that of combustible cigarettes: a preliminary report. Tobacco Control, 25(e1), e6-e9. doi:10.1136/tobaccocontrol-2013-052447.

Robinson, R. J., Hensel, E. C., Roundtree, K. A., Difrancesco, A. G., Nonnemaker, J. M., \& Lee, Y. O. (2016). Week long topography study of young adults using electronic cigarettes in their natural environment. PLOS One. doi:10.1371/journal.pone.0164038.

Rubinstein, M. L., Benowitz, N. L., Auerback, G. M., \& Moscicki, A. (2009). Withdrawal in adolescent light smoker following 24-hour abstinence. Nicotine \& Tobacco Research, 11(2), 185-189. doi:10.1093/ntr/ntn028.

Sims, T. H., McAfee, T., Fraser, D. L., Baker, T. B., Fiore, M. C., \& Smith, S. S. (2012).

Qutiline cessation counseling for young adult smokers: a randomized clinical trial. Nicotine \& Tobacco Research, 15(5), 932-941. doi:10.1093/ntr/nts227.

Shihadeh, A., \& Eissenberg, T. (2015). Electronic cigarette effectiveness and abuse liability: predicting and regulating nicotine flux. Nicotine \& Tobacco Research, 17(2), 158-162. doi:10.1093/ntr/ntu175.

Shrout, P. E., \& Fleiss, J. L. (1979). Intraclass correlations: Uses in assessing rater reliability. Psychological Bulletin, 86(2), 420-428.

Spindle, T. R., Breland, A. B., Karaoghlanian, N. V., Shihadeh, A. L., \& Eissenberg, T. (2015a). Preliminary results of an examination of electronic cigarette user puff topography: the effect of a mouthpiece-based topography measurement device on plasma nicotine and subjective effects. Nicotine \& Tobacco Research, 17(2), 142-149. doi:10.1093/ntr/ntu186. 
Spindle, T. R., Hiler, M. H., Breland, A. B., Karaoghlanian, N. V., Shihadeh, A. L., \& Eissenberg, T. (2016). The influence of a mouthpiece-based topography measurement device on electronic cigarette user's plasma nicotine concentration, heart rate, and subjective effects under directed and ad libitum use conditions. Nicotine \& Tobacco Research. doi:10.1093/ntr/ntw174. (Epub ahead of print).

Spindle, T., Pettaway, K., Breland, A., Karaoghlanian, N., Shihadeh, A., \& Eissenberg, T. (2015b). Does electronic cigarette liquid nicotine concentration and user experience influence puff topography?. Poster presented at the 21 st annual meeting of the Society for Research on Nicotine and Tobacco, Philadelphia, PA, February.

St. Helen, G., Ross, K. C., Dempsey, D. A., Havel, C. M., Jacob III, P. \& Benowitz, N. L. (2016). Nicotine delivery and vaping behavior during ad libitum e-cigarette access. Tobacco Regulatory Science, 2(4), 363-376.

Stratton, K., Shetty, P. \& Wallace, R. (2001). Clearing the smoke: the science base for tobacco harm reduction - executive summary. Tobacco Control, 10, 189-195. doi:10.1136/tc.10.2.189.

Sutfin, E. L., McCoy, T. P., Morrell, H. E. R., Hoeppner, B. B., \& Wolfson, M. (2013). Electronic cigarette use by college students. Drug and Alcohol Dependence, 131, 214221. http://dx.doi.org/10.1016/j.drugalcdep.2013.05.001.

Sutton, S. R., Russell, M. A. H., Iyer, R., Feyerabend, C., \& Saloojee, Y. (1982). Relationship between cigarette yields, puffing patterns, and smoke intake: evidence for tar compensation?. British Medical Journal, 285, 600-603. 
Tackett, A. P., Lechner, W. V., Meier, E., \& Grant, D. M. (2015). Biochemically verified smoking cessation and vaping beliefs among vape store customers. Addiction, 110(5), 868-874. doi:10.1002/add.12878

Talih, S., Balhas, Z., Eissenberg, T., Salman, R., Karaoghlanian, N., El Hallani, A., .. . Shihadeh, A. (2015). Effects of user puff topography, device voltage, and liquid nicotine concentration on electronic cigarette nicotine yield: Measurements and model predictions. Nicotine \& Tobacco Research, 17(2), 150-157. doi:10.1093/ntr/ntu174.

Tiffany, S. T., \& Drobes, D. J. (1991). The development and initial validation of a questionnaire on smoking urges. British Journal of Addiction, 86, 1467 - 1476.

Trehy, M. L., Ye, W., Hadwiger, M. E., Moore, T. W., Allgire, J. F., Woodruff, J. T., .. . Westenberger, B.J. (2011). Analysis of electronic cigarette cartridges, refill solutions, and smoke for nicotine and nicotine related impurities. Journal of Liquid Chromatography \& Related Technologies, 34, 1442-1458. doi:10.1080/10826076.2011.572213.

Trtchounian, A., Williams, M., \& Talbot, P. (2010). Conventional and electronic cigarettes (ecigarettes) have different smoking characteristics. Nicotine \& Tobacco Research, 12(9), 905-912. doi:10.1093/ntr/ntq114.

U.S. Department of Health and Human Services. (1990). The health benefits of smoking cessation: a report of the Surgeon General (DHHS Publication No. CDC 90-8416). Rockville, MD: U.S. Department of Health and Human Services, Public Health Service.

U.S. Department of Health and Human Services. (2004). The health consequences of smoking: a report of the Surgeon General. Rockville, MD: U.S. Department of Health and Human Services, Public Health Service. 
U.S. Department of Health and Human Services. (2010). How tobacco smoke causes diseasethe biology and behavioral basis for smoking-attributable disease: a report of the Surgeon General. Atlanta, GA: U.S. Department of Health and Human Services, Centers for Disease Control and Prevention, National Center for Chronic Disease Prevention and Health Promotion, Office on Smoking and Health.

U.S. Department of Health and Human Services. (2012). Preventing tobacco use among youth and young adults: a report of the Surgeon General. Atlanta, GA: U.S. Department of Health and Human Services, Centers for Disease Control and Prevention, National Center for Chronic Disease Prevention and Health Promotion, Office on Smoking and Health.

U.S. Department of Health and Human Services. (2014). The health consequences of smoking50 years of progress: a report of the Surgeon General. Atlanta, GA: U.S. Department of Health and Human Services, Centers for Disease Control and Prevention, National Center for Chronic Disease Prevention and Health Promotion, Office on Smoking and Health.

Vansickel, A. R., Cobb, C. O., Weaver, M. F., \& Eissenberg, T. E. (2010). A clinical laboratory model for evaluating the acute effects of electronic "cigarettes": Nicotine delivery profile and cardiovascular and subjective effects. Cancer Epidemiology, Biomarkers \& Prevention, 19(8), OF1-OF9. doi:10.1158/1055-9965.EPI-10-0288.

Vansickel, A. R., \& Eissenberg, T. (2013). Electronic cigarettes: Effective nicotine delivery after acute administration. Nicotine \& Tobacco Research, 15(1), 267-270. doi:10.1093/ntr/ntr316.

Wagener, T. L., Meier, E., Hale, J. J., Oliver, E. R., Warner, M. L., Driskill, L .M., . . Foster, S. (2014). Pilot investigation of changes in readiness and confidence to quit smoking after e- 
cigarette experimentation and 1 week of use. Nicotine \& Tobacco Research, 16(1), 108114. doi:10.1093/ntr/ntt138.

Yan, X. S., \& D’Ruiz, C. (2015). Effects of using electronic cigarettes on nicotine delivery and cardiovascular function in comparison with regular cigarettes. Regulatory Toxicology and Pharmacology, 71, 24-34. http://dx.doi.org/10.1016/j.yrtph.2014.11.004.

Zacny, J. P. and Stitzer, M. L. (1988). Cigarette brand-switching: effects on smoke exposure and smoking behavior. Journal of Pharmacology and Experimental Therapeutics, 246(2), 619-627.

Zacny, J. P., Stitzer, M. L., Brown, F. J., Yingling, J. E., and Griffiths, R. R. (1987). Human cigarette smoking: effects of puff and inhalation parameters on smoke exposure. Journal of Pharmacology and Experimental Therapeutics, 240(2), 554-564. 
Table 1

Mean (SD) or \% for demographic and product use characteristics

\begin{tabular}{lccc}
\hline & $\begin{array}{c}\text { Total } \\
(\mathrm{N}=12)\end{array}$ & $\begin{array}{c}\text { ECIG-Experienced } \\
(\mathrm{n}=7)\end{array}$ & $\begin{array}{c}\text { ECIG-Naïve } \\
(\mathrm{n}=5)\end{array}$ \\
\hline Age (years) & $28.75(11.48)$ & $28.00(11.33)$ & $29.80(12.95)$ \\
$\%$ Male & 100 & 100 & 100 \\
$\%$ White & 83 & 86 & 80 \\
$\%$ Non-Hispanic & 100 & 100 & 100 \\
Education (years) & $14.00(2.62)$ & $14.70(3.04)$ & $13.00(1.73)$ \\
Cigarettes Per Day & & & $14.60(3.65)$ \\
Years Smoking & & & $4.00(6.16)$ \\
Carbon Monoxide (ppm) & & & $19.60(13.72)$ \\
FTND Score & & & $4.80(1.64)$ \\
Penn State ECIG Dependence Index & & & \\
ECIG Liquid Per Day (ml) & & $4.29(4.03)$ & \\
Years ECIG Use & & $1.96(1.21)$ & \\
ECIG Liquid Nicotine (mg/ml) & \multicolumn{3}{|}{$12.86(7.29)$} \\
\hline
\end{tabular}

${ }^{\mathrm{a}}$ Fagerstrom Test for Nicotine Dependence (range 0-10)

${ }^{\mathrm{b}}$ Penn State ECIG Dependence Index (range 0-20) 
Table 2

Correlation coefficients for rater scores by operational definition

\begin{tabular}{ccc} 
& Lip Definition & Light Definition \\
\hline Puff Number $^{\mathrm{a}}$ & & \\
Directed & $0.56^{*}$ & $0.80^{* *}$ \\
Ad lib 1 & $1.00^{* *}$ & $0.91 * *$ \\
Ad lib 2 & $1.00^{* *}$ & $0.94 * *$ \\
& & \\
Puff Duration & & \\
Directed & $0.92^{* *}$ & $0.93 * *$ \\
Ad lib 1 & $0.95^{* *}$ & $0.87 * *$ \\
Ad lib 2 & $0.96^{* *}$ & $0.97 * *$ \\
Inter-Puff-Interval & & \\
Directed & & $0.42^{* *}$ \\
Ad lib 1 & $0.56^{* *}$ & $0.98^{* *}$ \\
Ad lib 2 & $0.99 * *$ & $1.00^{* *}$ \\
\hline
\end{tabular}

$* * p<.01, * p<.05$

${ }^{a}$ Data analyzed using Intraclass Correlation

${ }^{\mathrm{b}}$ Data analzyed using Pearson's Correlation Coefficient 
Table 3

Statistical analysis results for comparisons between measurement methods

\begin{tabular}{lcccccc}
\hline & \multicolumn{3}{c}{ Paired-Samples T-tests $^{\mathrm{a}}$} & \multicolumn{3}{c}{ Means (SEMs) } \\
& eTop vs. eTop 2.0 & eTop vs. Video $^{\mathrm{c}}$ & eTop 2.0 vs. Video $^{\mathrm{d}}$ & eTop & eTop 2.0 & Video (Lip) \\
\hline Puff Number & -0.32 & 0.46 & 0.19 & $11.36(1.05)$ & $11.12(1.36)$ & $11.03(1.22)$ \\
Puff Duration (sec) & 1.66 & -1.23 & -0.33 & $3.64(0.48)$ & $3.91(0.46)$ & $4.05(0.48)$ \\
Inter-Puff-Interval (sec) & 1.52 & -0.96 & 0.96 & $28.48(4.88)$ & $34.05(10.24)$ & $30.84(6.19)$ \\
Puff Volume (ml) & $\mathrm{n} / \mathrm{a}$ & $\mathrm{n} / \mathrm{a}$ & $\mathrm{n} / \mathrm{a}$ & $74.7(14.88)$ & $50.45(8.95)$ & $\mathrm{n} / \mathrm{a}$ \\
Flow Rate (ml/sec) & $\mathrm{n} / \mathrm{a}$ & $\mathrm{n} / \mathrm{a}$ & $\mathrm{n} / \mathrm{a}$ & $21.16(3.42)$ & $13.64(1.91)$ & $\mathrm{n} / \mathrm{a}$ \\
\hline
\end{tabular}

${ }^{\mathrm{a}}$ Data for the video condition based on the lip definition; All p's $>0.05$

bdf: 35 (puff number), 32 (puff duration), and 32 (IPI)

cdf: 33 (puff number), 33 (puff duration), and 33 (IPI)

d df: 35 (puff number), 32 (puff duration), and 34 (IPI) 
Table 4

Correlation coefficients for data collected via computerized device and direct observation methods

\begin{tabular}{|c|c|c|c|c|c|c|}
\hline & \multicolumn{3}{|c|}{ ECIG-Experienced } & \multicolumn{3}{|c|}{ ECIG-Naïve } \\
\hline & 1 & 2 & 3 & 1 & 2 & 3 \\
\hline \multicolumn{7}{|l|}{ eTop2 vs. Video } \\
\hline \multicolumn{7}{|l|}{ Puff Number } \\
\hline Lip Definition & -0.17 & $0.88 * *$ & $0.89 * *$ & 0.41 & 0.62 & -0.34 \\
\hline Light Definition & -0.55 & $0.94 * *$ & $0.96^{* *}$ & 0.51 & 0.05 & 0.03 \\
\hline \multicolumn{7}{|l|}{ PuffDuration } \\
\hline Lip Definition & $0.59 * *$ & $0.47 * *$ & 0.23 & $0.60 * *$ & $0.59 * *$ & $0.38 * *$ \\
\hline Light Definition & $0.53 * *$ & $0.38 * *$ & $0.26^{*}$ & $0.78 * *$ & $0.49 * *$ & 0.20 \\
\hline \multicolumn{7}{|l|}{ Inter-Puff-Interval } \\
\hline Lip Definition & -0.06 & $0.69 * *$ & $0.63 * *$ & -0.08 & 0.22 & 0.29 \\
\hline Light Definition & -0.06 & 0.23 & $0.65 * *$ & -0.03 & 0.29 & 0.33 \\
\hline \multicolumn{7}{|l|}{ eTop vs. Video } \\
\hline \multicolumn{7}{|l|}{ Puff Number } \\
\hline Lip Definition & -0.28 & $0.86^{*}$ & $0.91 *$ & 0.41 & 0.8 & $0.98 * *$ \\
\hline Light Definition & -0.06 & $0.97 * *$ & $0.95 * *$ & 0.51 & 0.08 & 0.8 \\
\hline \multicolumn{7}{|l|}{ Puff Duration } \\
\hline Lip Definition & $0.55 * *$ & $0.30 *$ & $0.30 *$ & $0.50 * *$ & $0.50 * *$ & $0.29 *$ \\
\hline Light Definition & $0.52 * *$ & 0.20 & $0.40 * *$ & $0.68^{* *}$ & $0.41^{*}$ & 0.19 \\
\hline \multicolumn{7}{|l|}{ Inter-Puff-Interval } \\
\hline Lip Definition & -0.06 & $0.48^{* *}$ & $0.28 *$ & -0.06 & $0.48 * *$ & 0.28 \\
\hline Light Definition & -0.05 & 0.10 & $0.36^{*}$ & -0.05 & $0.42 *$ & 0.18 \\
\hline
\end{tabular}

$* * p<.01, * p<.05$ 
Table 5

Correlation coefficients for topography via computerized devices and videos of computerized device use

\begin{tabular}{ccccccc}
\hline & ECIG-Experienced & \multicolumn{3}{c}{ ECIG-Naïve } \\
& 1 & 2 & 3 & 1 & 2 & 3
\end{tabular}

eTop2 vs. Video of eTop2

Puff Number

$\begin{array}{lcccccc}\text { Lip Definition } & \mathrm{n} / \mathrm{a}^{\mathrm{a}} & 1.00^{* *} & 1.00^{* *} & 0.17 & 0.17 & 0.78 \\ \text { Light Definition } & 0.28 & 0.89^{* *} & 0.88^{* *} & -0.04 & -0.42 & 0.86\end{array}$

Puff Duration

$\begin{array}{lllllll}\text { Lip Definition } & 0.86^{* *} & 0.95^{* *} & 0.82^{* *} & 0.95^{* *} & 0.84^{* *} & 0.93^{* *} \\ \text { Light Definition } & 0.85^{* *} & 0.88^{* *} & 0.91^{* *} & 0.98^{* *} & 0.81 * * & 0.94 * *\end{array}$

Inter-Puff-Interval

$\begin{array}{lllllll}\text { Lip Definition } & 0.10 & 0.99^{* *} & 0.98^{* *} & 0.66^{* *} & 0.95^{* *} & 0.84^{* *} \\ \text { Light Definition } & 0.08 & 1.00^{* *} & 0.99^{* *} & 0.74^{* *} & 0.94^{* *} & 0.86^{* *}\end{array}$

eTop vs. Video of eTop

Puff Number

$\begin{array}{lcccccc}\text { Lip Definition } & 0.18 & 0.99 * * & 0.99 * * & 0.61 & 0.93 * & 0.55 \\ \text { Light Definition } & -0.27 & 0.97 * * & 0.99 * * & -0.69 & -0.10 & 0.57\end{array}$

Puff Duration

$\begin{array}{lllllll}\text { Lip Definition } & 0.95 * * & 0.76^{* *} & 0.95^{* *} & 0.93^{* *} & 0.99^{* *} & 0.99 * * \\ \text { Light Definition } & 0.92 * * & 0.47^{* *} & 0.92^{* *} & 0.93^{* *} & 0.85^{* *} & 0.95 * *\end{array}$

Inter-Puff-Interval

$\begin{array}{lllllll}\text { Lip Definition } & 0.35 * * & 1.00^{* *} & 1.00^{* *} & 0.99 * * & 0.90^{* *} & 0.75 * * \\ \text { Light Definition } & 0.73 * * & 0.99 * * & 1.00^{* *} & 0.56^{* *} & 0.88^{* *} & 0.52 *\end{array}$

$* * p<.01, * p<.05$

${ }^{\mathrm{a}} \mathrm{n} / \mathrm{a}$ due to lip definition having a constant value (i.e., all values are 10 puffs) 
Table 6

Mean (SD) for puff topography measures for device by group

\begin{tabular}{lcccccc}
\hline & \multicolumn{2}{c}{ eTop 2.0 } & \multicolumn{2}{c}{ eTop } & \multicolumn{2}{c}{ Video } \\
& ECIG- Naïve & ECIG-Experienced & ECIG- Naïve & ECIG-Experienced & ECIG- Naïve & ECIG-Experienced \\
\hline Puff Number & $10.33(1.40)$ & $10.62(6.84)$ & $11.53(2.61)$ & $10.05(5.28)$ & $10.10(1.86)$ & $10.64(6.10)$ \\
Puff Volume (ml) & $62.22(39.52)$ & $41.17(18.49)$ & $89.38(64.71)$ & $62.40(34.67)$ & $\mathrm{n} / \mathrm{a}$ & $\mathrm{n} / \mathrm{a}$ \\
Puff Duration (sec) & $3.89(1.88)$ & $3.91(1.38)$ & $3.77(2.01)$ & $3.52(1.35)$ & $4.49(2.10)$ & $3.58(1.17)$ \\
Inter-Puff-Interval (sec) & $28.11(5.94)$ & $39.24(47.36)$ & $25.84(5.66)$ & $30.63(22.39)$ & $28.37(6.31)$ & $33.01(28.48)$ \\
Flow Rate (ml/sec) & $16.27(7.98)$ & $11.16(4.47)$ & $24.91(14.04)$ & $18.03(8.91)$ & $\mathrm{n} / \mathrm{a}$ & $\mathrm{n} / \mathrm{a}$ \\
\hline
\end{tabular}

Data are collapsed across bout 
Table 7

Mean (SD) for acceptability items for device by group

\begin{tabular}{lcccccc}
\hline & \multicolumn{2}{c}{ eTop 2.0 } & \multicolumn{2}{c}{ eTop } & \multicolumn{2}{c}{ Video } \\
& ECIG- Naïve & ECIG-Experienced & ECIG- Naïve & ECIG-Experienced & ECIG- Naïve & ECIG-Experienced \\
\hline Alter Behavior & $46.60(32.08)$ & $15.29(37.39)$ & $44.40(39.77)$ & $24.57(38.09)$ & $38.00(22.12)$ & $23.43(37.05)$ \\
Less Likely & $34.60(31.32)$ & $14.57(28.48)$ & $32.60(38.42)$ & $20.71(36.55)$ & $32.60(33.34)$ & $7.14(16.32)$ \\
Reduce Enjoyment & $29.00(25.23)$ & $28.71(33.88)$ & $25.60(24.76)$ & $35.43(38.11)$ & $40.2(30.74)$ & $21.29(39.22)$ \\
Affect Taste & $39.60(38.21)$ & $16.71(27.88)$ & $29.20(27.36)$ & $34.14(39.41)$ & $13.20(15.55)$ & $13.43(17.96)$ \\
More Difficult & $36.80(34.45)$ & $38.14(45.18)$ & $23.20(24.30)$ & $33.00(40.44)$ & $24.40(18.04)$ & $7.29(16.40)$ \\
Increase Awareness & $44.20(27.46)$ & $22.14(25.60)$ & $27.80(18.99)$ & $35.86(38.56)$ & $47.00(28.11)$ & $25.14(28.23)$ \\
Like to Know More & $51.60(41.38)$ & $76.14(35.44)$ & $50.40(33.84)$ & $70.43(34.28)$ & $59.60(33.10)$ & $69.00(30.94)$ \\
\hline Data
\end{tabular}

Data are collapsed across bout 
Table 8

Mean (SE) for subjective outcomes and heart rate at different timepoints

\begin{tabular}{lccc} 
& Baseline & Post-directed & Post-ad lib 1 \\
\hline Hughes Hatsukami & & & \\
$\quad$ Urges & $50.67(10.21)$ & $24.64(6.36)$ & $19.06(5.41)$ \\
$\quad$ Irritable & $27.11(9.52)$ & $7.17(3.35)$ & $4.75(2.55)$ \\
$\quad$ Craving & $51.31(10.35)$ & $21.58(5.48)$ & $17.33(6.07)$ \\
& & & \\
Tiffany Drobes QSU & $18.06(3.01)$ & $10.14(2.18)$ & $8.06(2.11)$ \\
$\quad$ Factor 1 & $7.22(2.22)$ & $2.89(1.08)$ & $1.86(0.99)$ \\
$\quad$ Factor 2 & & & \\
& & & \\
Direct Effects of ECIG & $10.75(6.47)$ & $47.14(11.60)$ & $46.42(11.63)$ \\
Use & $9.94(5.99)$ & $43.14(10.77)$ & $42.39(11.41)$ \\
$\quad$ Satisfying & $9.33(5.35)$ & $26.50(9.87)$ & $31.58(10.96)$ \\
$\quad$ Pleasant & & & \\
$\quad$ Taste Good & $72.73(2.68)$ & $79.53(2.58)$ & $77.06(2.34)$ \\
\hline
\end{tabular}

Data are collapsed across measurement method and group

Scores at the post-directed bout and post-ad lib 1 bout are significantly different from scores at baseline for all outcomes shown 


\section{Appendix A}

Telephone Screening Questionnaire

\section{Date:}

Interviewer:

Interviewer: "I would like to ask you some questions about yourself and your health status as well as your use of tobacco, alcohol, and other drugs. The purpose of these questions is to determine whether or not you are eligible to participate in the study that I just described to you. All of your responses are confidential. You are not required to answer any question and you may stop this interview at any time. May I begin the questions?”

Document caller's response by circling either: $\quad$ Yes $\quad$ or $\quad$ No

If Yes: begin form. If No: thank the caller and stop the interview.

How did you hear about us/our study?

Personal Information:

1. "What is your first name?"

2. "What is a phone number at which you can be contacted?"

3. "If we call and you are not available, may we leave a message?"

4. "What is your date of birth?"

General health status:

1. "Are you currently under a doctor's care for a medical condition?" Yes or No

If Yes: "Please describe the concern or problem":

2. "Do you have any chronic health concerns or problems?" Yes or No

If Yes: "Please describe the condition":

3. "Are you taking any prescription or over-the-counter medications?" Yes or No

If Yes: "Please identify the medication":

4. Do you have any psychiatric conditions like depression or anxiety? Yes or No

If Yes: "Please describe the condition":

5. "Have you ever been diagnosed with high or low blood pressure?" Yes or No

If Yes: "Please indicate whether it is high or low":

For women only:

6. "Are you currently pregnant?"

Yes or No

7. "Are you currently breast-feeding a child?"

Yes or No

\section{Cigarette Use:}

1. "Do you currently smoke tobacco cigarettes?"

Yes or No

If No: Skip to the section on electronic cigarette use

2. "What brand of cigarettes do you smoke?"

Regular/Light / Ultra-light Hard / Soft Pack Regular/Menthol Regular/100s / Other 
3. "On average, how many cigarettes do you smoke per day?"

(numb of cigs)

[Guide to report one number that best represents their average/day; do not provide a range]

4. "For how long have you smoked this number per day?"

(months / years)

\section{Electronic Cigarette Use:}

1. "Do you currently use an electronic cigarette?" Yes or No

If No: Skip to the section on other tobacco use

2. "What model/brand of ECIG do you own?

a) If own multiple, which do you use most frequently?

3. "What nicotine concentration of e-liquid do you use?"

4. "What flavor of e-liquid do you use?"

5. "On average, how many days per week do you use an ECIG?"

6. "How much e-liquid/How many cartridges do you use per day?

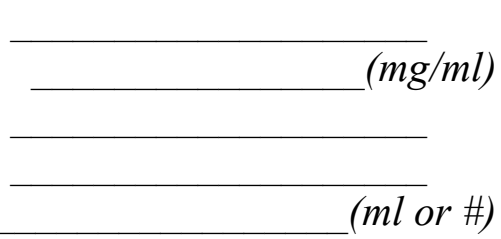

[Guide to report one number that best represents their average/day; do not provide a range]

7. "For how long have you used that amount of product?"

(months / years)

Other Tobacco Use:

1. "Have you used any of the following other nicotine/tobacco products in the past month?"

\begin{tabular}{|c|c|c|c|}
\hline & & $\begin{array}{c}\text { If 'yes', estimate how many days } \\
\text { you have used this product in the } \\
\text { past month? }\end{array}$ \\
\hline $\begin{array}{c}\text { Large cigars } \\
\begin{array}{c}\text { Cigarillos (e.g., Black \& Milds) } \\
\text { or small cigars }\end{array}\end{array}$ & No & Yes & \\
\hline $\begin{array}{c}\text { Waterpipe (a.k.a. hookah or } \\
\text { shisha) }\end{array}$ & No & Yes & \\
\hline $\begin{array}{c}\text { Smokeless tobacco } \\
\text { (snuff/dip/chew/snus) }\end{array}$ & No & Yes & \\
\hline $\begin{array}{c}\text { Electronic Cigarette (if cigarette } \\
\text { smoker) }\end{array}$ & No & Yes & \\
\hline \begin{tabular}{c} 
Other: \\
\hline
\end{tabular} & No & Yes & \\
\hline
\end{tabular}

\section{Smoking Cessation History:}

1. "Are you currently using any nicotine replacement products?" $\quad$ Yes or No

(e.g., patch, gum, inhaler, nasal spray)

2. "Are you currently using any prescription medications for cessation?" Yes or No (e.g., Chantix, Zyban, etc.) 


\section{Illicit Drug Use:}

1. "Have you used any of the following other drugs for recreational purposes in the past month?"

\begin{tabular}{|c|c|c|c|}
\hline & & & $\begin{array}{c}\text { If 'yes', estimate how many } \\
\text { days you have used this } \\
\text { product in the past month? }\end{array}$ \\
\hline Alcohol & No & Yes & \\
\hline Marijuana / Spice / K2 & No & Yes & \\
\hline $\begin{array}{c}\text { Stimulants (e.g., } \\
\text { cocaine, }\end{array}$ & No & Yes & \\
\hline $\begin{array}{c}\text { Opiates (e.g., heroin, } \\
\text { oxycodone, }\end{array}$ & No & Yes & \\
\hline Other: & No & Yes & \\
\hline
\end{tabular}

Interviewer: "Thank you for responding to these questions. I need to pass on your responses to the principal investigator who will then determine whether or not you are eligible to participate in a study. If you are eligible, someone will contact you within approximately one week. If you are not eligible for this study, then you will not be contacted."

[If respondent does not have a phone, they can call us back in a few days] 
Appendix B

Demographic Information

Participant ID:

Today's Date :

Age

Years:

Date of birth

\section{Ethnicity}

o Hispanic or Latino o Not Hispanic or Latino

\section{Race}

o American Indian/Alaskan Native o Asian/Native Hawaiian or other Pacific Islander
o Black or African American
o White
o Other/Unknown

\section{Gender}
o Male
o Female

\section{Marital status}
o Single
o Married
o Separated
o Divorced
o Widowed

\section{Education}

Years: (For example, High school $=12$, College degree $=16$, etc. $)$

\section{Primary employment}
o Unemployed
o Part Time (0-30 hrs/wk)
o Full Time ( $>30$ hrs/wk)
o Student 


\section{Appendix C}

\section{Medical History and Drug Use Form}

Participant ID:

Date:

\section{General health status:}

Are you under a doctor's care for a medical condition? below) (If yes, please describe

Are you taking any prescription medications? (If yes, please identify below)

Do you have any chronic health concerns or problems? (If yes, please describe below)

Do you have any psychiatric conditions? (If yes, please describe below)

\section{For women only:}

Are you currently pregnant? (yes or no)

Are you currently breast-feeding a child? (yes or no)

\section{Cigarette Use:}

Do you currently smoke tobacco cigarettes? (yes or no) if no, skip to the next section

On average, how many cigarettes per day do you smoke? (number of cigarettes)

For how long have you smoked the above number of cigarettes per day? (months or years)

What brand of cigarettes do you smoke?

Regular, light, or ultra-light?

Menthol or Non-menthol?

Hard pack or soft pack?

King size or 100 s?

\section{ECIG Use:}

Do you currently use an ECIG? (yes or no) if no, skip to the next section 
How many days per week do you use an ECIG? (number of days)

On average, how much e-liquid/how many cartidges do you use per day?

(milliliters or number)

What nicotine concentration of e-liquid do you use? $(\mathrm{mg} / \mathrm{ml}$ or $\%)$

For how long have you been using an ECIG? (months/years)

What model ECIG do you use most frequently?

What flavor of e-liquid do you use most frequently?

\section{History of Quit Attempts:}

Have you ever made an attempt to quit or reduce your smoking? skip to the next section (yes or no) if no,

Have you made any attempts to quit or reduce your smoking in the last 30 days?

\section{Other Tobacco Use:}

Do you currently use any other nicotine/tobacco products? (yes or no)

Circle all products below that you have used in the past 30 days:

Cigars / cigarillos / small cigars Smokeless tobacco (snuff, dip, chew) / snus

Hookah / waterpipe Electronic cigarette

Nicotine gum / patch / lozenge / inhaler Other:

\section{Alcohol Use:}

Have you used alcohol in the past month? (yes or no) if no, skip to the next section How many days out of the last 30 have you used alcohol? (number of days)

Have you ever been treated for alcohol abuse/dependence? (yes or no)

\section{Other Drug Use:}

Have you used any illegal drugs within the past month? (yes or no)

If yes, please identify which drugs: 


\section{Appendix D}

Fagerström Test for Nicotine Dependence

Please answer the following questions (mark an $\mathrm{X}$ in one box only):

1. How soon after you wake up do you smoke your first cigarette?
Within
Within
Within
After
5 minutes
6-30 minutes
31-60 minutes
60 minutes
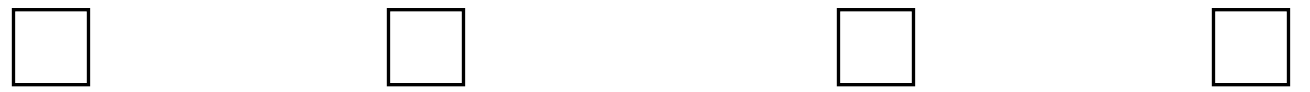

2. Do you find it difficult to refrain from smoking in places where it is forbidden (e.g., in church, at the library, at the movies)?

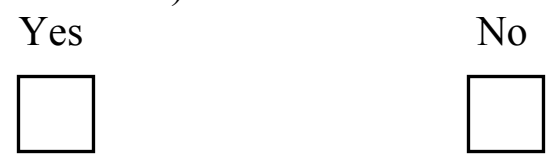

3. Which cigarette would you hate to give up the most?

The first one in the morning

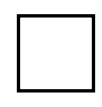

All others

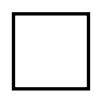

4. How many cigarettes a day do you smoke?

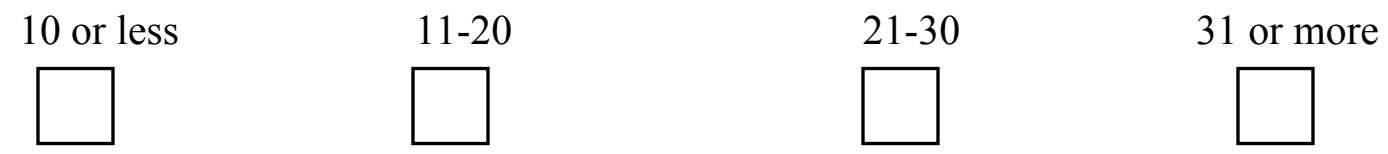

5. Do you smoke more frequently during the first hours after waking than during the rest of the day?

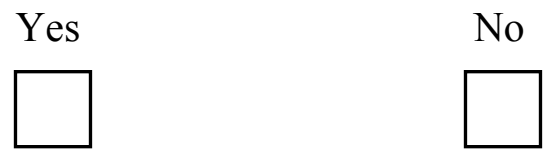

6. Do you smoke if you are so ill that you are in bed most of the day?

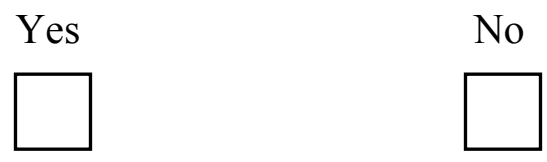




\section{Appendix E}

Penn State Electronic Cigarette Dependence Index

\section{Please answer the following questions (mark an $\mathrm{X}$ in one box only):}

1. How many times per day do you usually use your electronic cigarette? (assume that one "time" consists of around 15 puffs or lasts around 10 minutes)
$0-4$
$5-9$
$10-14$
$15-19$
20-29
$30+$
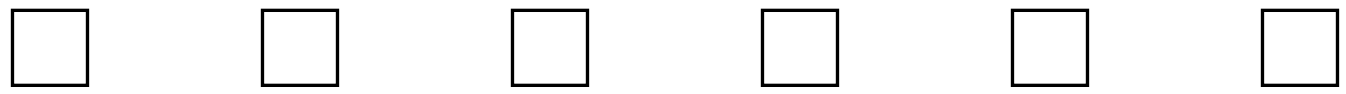

2. On days that you can use your electronic cigarette freely, how soon after you wake up do you first use your electronic cigarette?

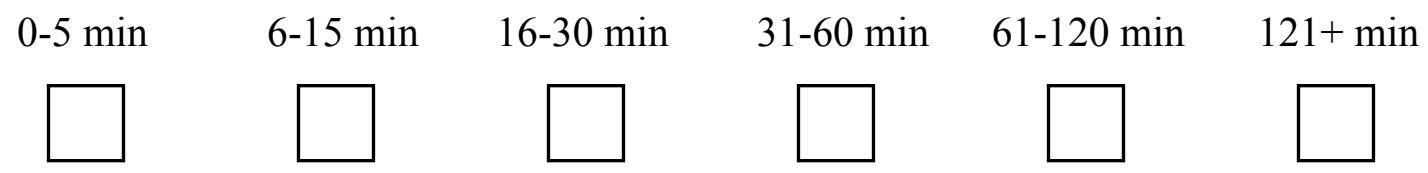

3. Do you sometimes awaken at night to use your electronic cigarette?

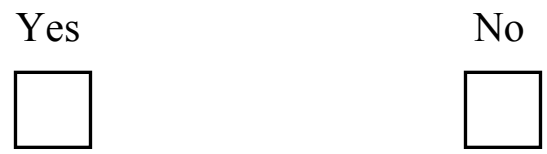

4. If yes, how many nights per week do you typically awaken to use your electronic cigarette?

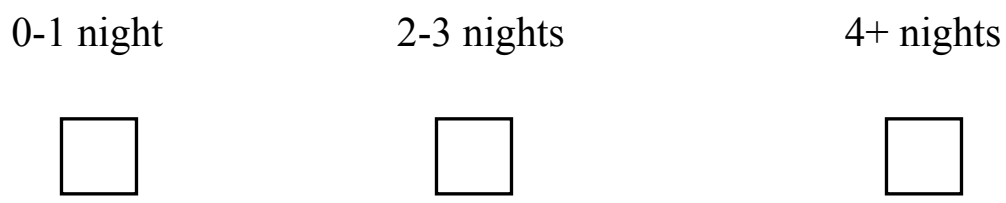

5. Do you use an electronic cigarette now because it is really hard to quit?

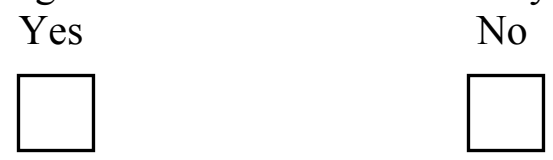

6. Do you ever have strong cravings to use an electronic cigarette?

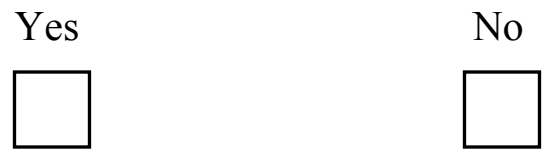


7. Over the past week, how strong have the urges to use an electronic cigarette been?

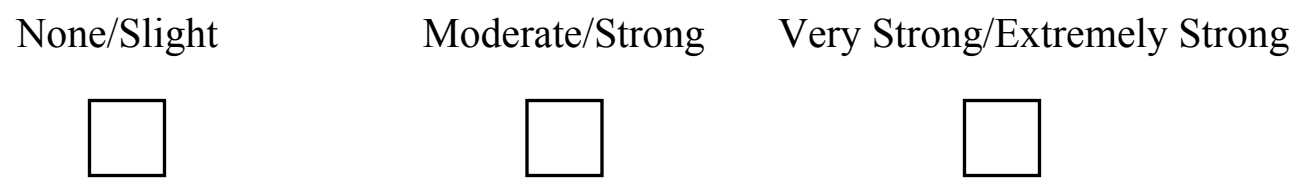

8. Is it hard to keep from using an electronic cigarette in places where you are not supposed to?

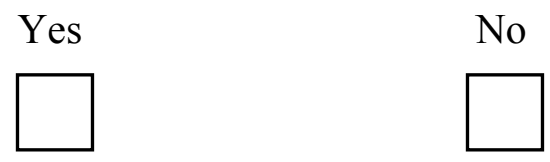

When you haven't used an electronic cigarette for a while or you tried to stop using...

9. Did you feel more irritable because you could use and electronic cigarette?

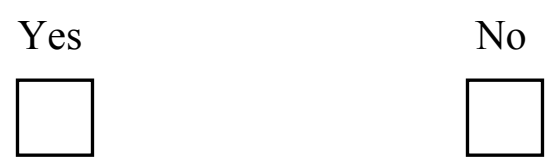

10. Did you feel nervous, restless, or anxious because you couldn't use an electronic cigarette?

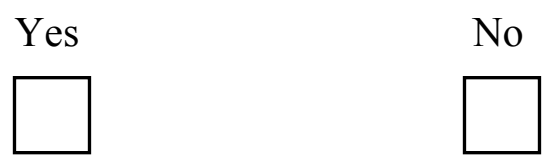


Appendix F

Acceptability Questionnaire

Please respond to each question by making a vertical mark anywhere along the horizontal line.

Did the laboratory environment and/or the computerized equipment:

Not at all

Extremely

1. Alter your smoking behavior today?

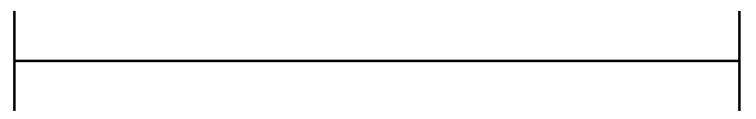

2. Make you less likely to want to smoke today?

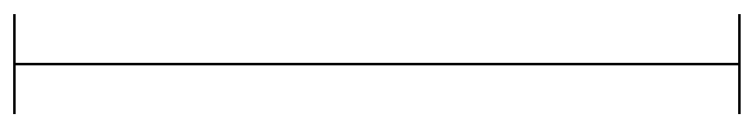

3. Reduce your smoking enjoyment today?

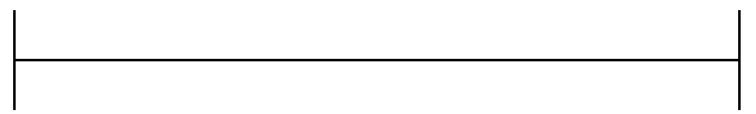

4. Affect the taste of the cigarettes you smoked today?

5. Make smoking more difficult today?

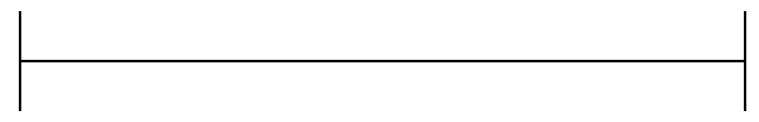

6. Increase your awareness of how much you smoked today?
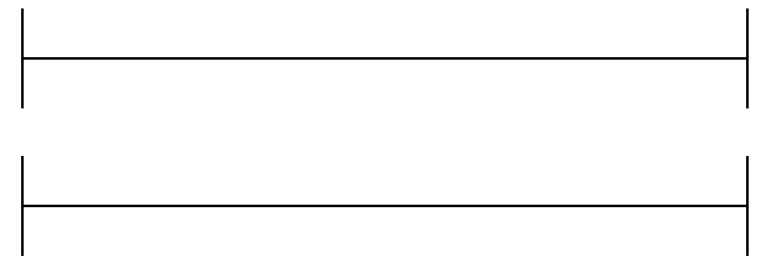


\section{Appendix G}

Hughes \& Hatsukami (1986)

These phrases may or may not describe how you feel right now. Please respond to each word or phrase with how you feel RIGHT NOW by drawing a vertical mark anywhere along the horizontal line.

Not at all

Extremely

1. URGES to smoke

2. Irritability/frustration/anger

3. Anxious

4. Difficulty concentrating

5. Restlessness

6. Hunger

7. Impatient

8. CRAVING a cigarette/nicotine

9. Drowsiness

10. Depression/feeling blue

11. Desire for sweets
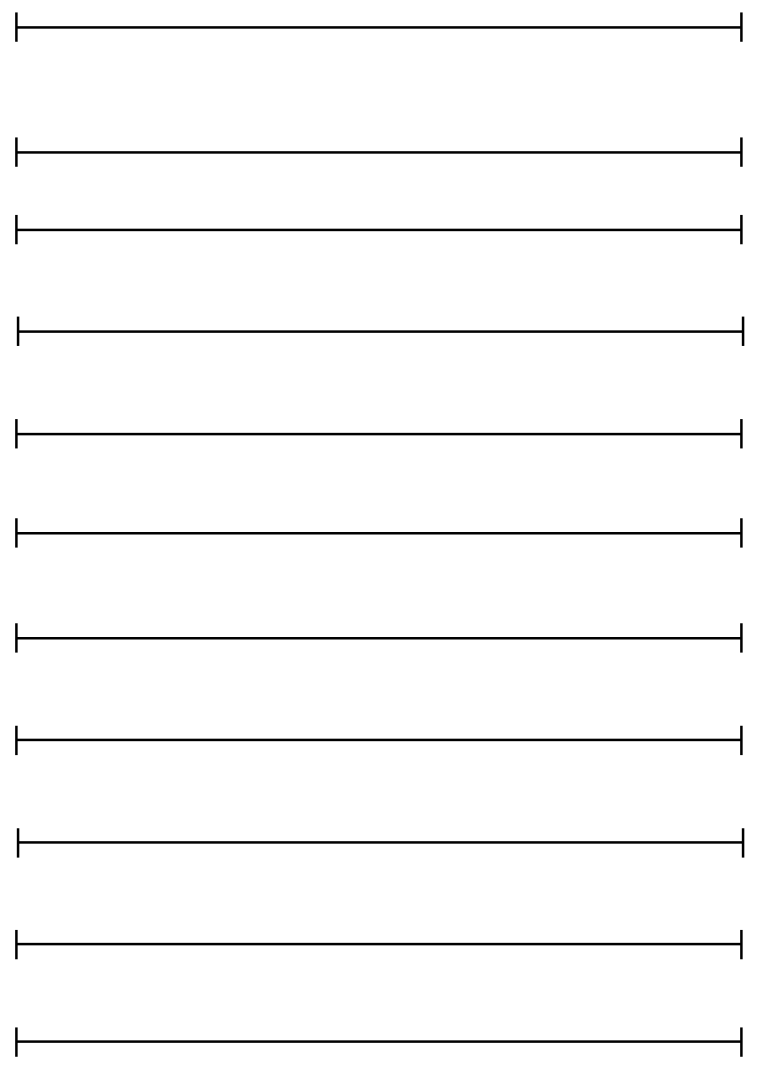


\section{Appendix $\mathrm{H}$}

\section{Questionnaire of Smoking Urges - Brief}

\section{For each item, please indicate how you feel RIGHT NOW.}

1. I have a desire for a cigarette right now.
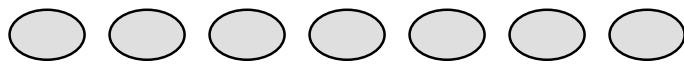

Strongly

Strongly

disagree agree

2. Nothing would be better than smoking a cigarette right now.
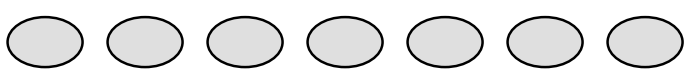

Strongly

Strongly

disagree agree

3. If it were possible, I probably would smoke now.
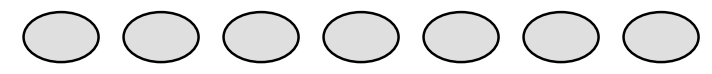

\section{Strongly}

Strongly

disagree agree

4. I could control things better right now if I could smoke.
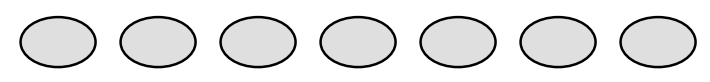

Strongly

Strongly

5. All I want right now is a cigarette.

disagree

6. I have an urge for a cigarette.

7. A cigarette would taste good now.

8. I would do almost anything for a cigarette now.

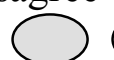

Strongly

disagree
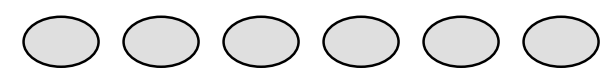
agree

Strongly

disagree
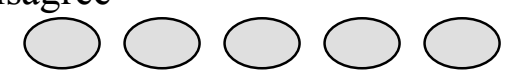

Strongly

Strongly

disagree

Strongly agree
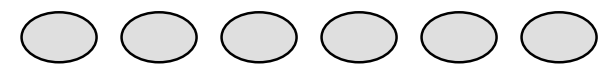

Strongly

Strongly disagree 
9. Smoking would make me less depressed.
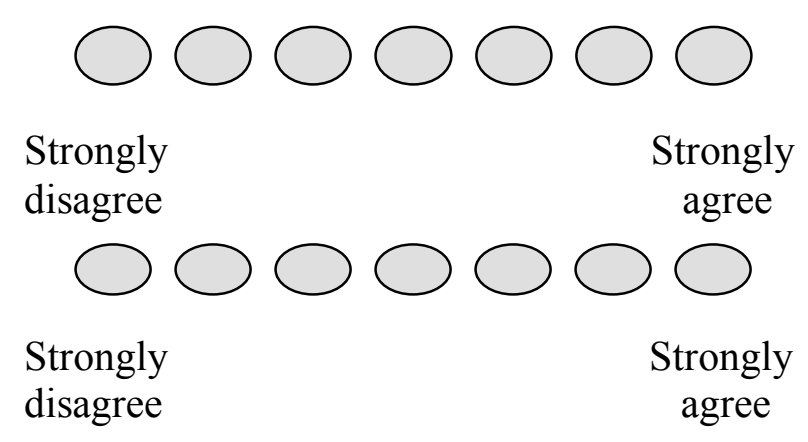

10. I am going to smoke as soon as possible.

Strongly

Strongly

disagree 


\section{Appendix I}

\section{Direct Effects of Nicotine Scale}

These phrases may or may not describe how you feel right now. Please respond to each word or phrase with how you feel RIGHT NOW by drawing a vertical mark anywhere along the horizontal line.

Not at all

1. Nauseous

2. Dizzy

3. Lightheaded

4. Nervous

5. Sweaty

6. Headache

7. Excessive salivation

8. Heart pounding

9. Confused

10. Weak
Extremely
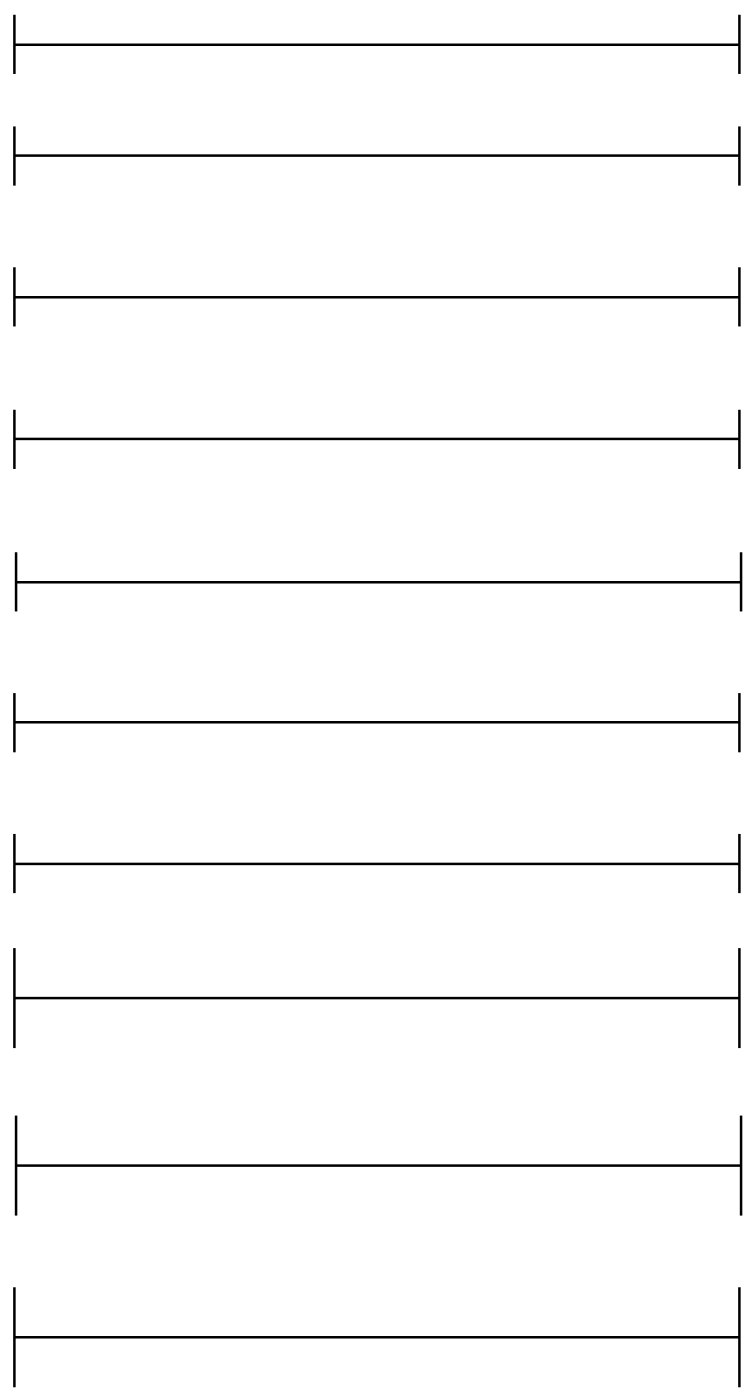


\section{Appendix $\mathbf{J}$}

\section{Direct Effects of ECIG USE}

These phrases may or may not describe how you feel right now. Please respond to each word or phrase with how you feel RIGHT NOW by drawing a vertical mark anywhere along the horizontal line.

\section{Not at all}

Extremely

1. Was the product satisfying?

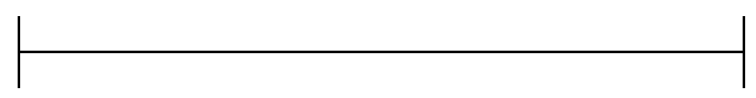

2. Was the product pleasant?

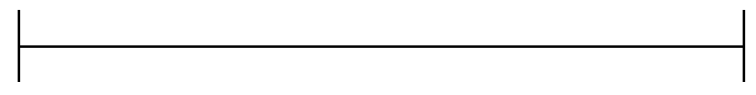

3. Did the product taste good?

4. Did the product make you dizzy?

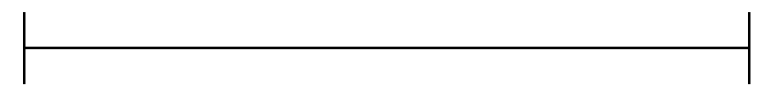

5. Did the product calm you down?

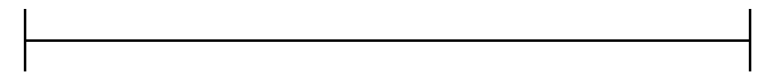

6. Did the product help you concentrate?

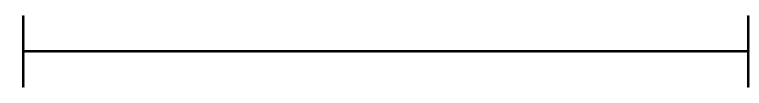

7. Did the product make you feel more awake?

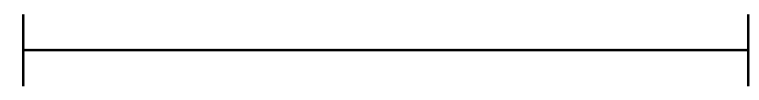

8. Did the product reduce your hunger for food?

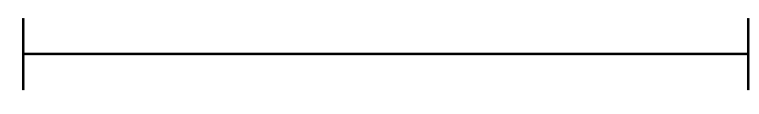

9. Did the product make you sick?

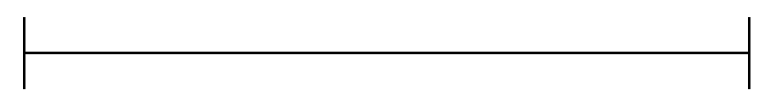

